Página inicial: 601 - Página final: 636

TIPO DE ARTÍCULO: de Investigación

\title{
DIAGNÓSTICO Y PROPUESTAS COMUNITARIAS PARA EL MEJORAMIENTO INTEGRAL DEL BARRIO, EL FARO, COMUNA 8. MEDELLÍN.
}

\author{
DIAGNOSIS AND COMMUNITY PROPOSAL FOR THE INTEGRAL IMPROVEMENT OF \\ THE "EL FARO" NEIGHBORHOOD IN THE "8TH" COMMUNE IN MEDELLIN.
}

\author{
Recibido: Enero 2014 Revisado: Marzo 2014 Aprobado: 1 de Mayo 2014 \\ Por: Carlos Velásquez ${ }^{1}$.
}

\section{RESUMEN.}

El presente texto presenta los resultados de un ejercicio investigativo. que visibiliza Por un lado las problemáticas más sentidas de los habitantes de las comunidades Golondrinas y El Faro de la Comuna 8 de la ciudad de Medellín, un ejercicio que se adelantó como respuesta ante los procesos de intervención institucional, derivados de los constantes procesos de transformación de la ciudad, los cuales, han generado desplazamientos y silencios frente a la realidad misma de dichas comunidades; por otro lado, presenta las propuesta de solución construidas desde las mismas comunidades ante dichos problemas.

\section{PALABRAS CLAVE.}

Territorio, transformación urbana, desarrollo, violencia, dignidad, derechos.

\section{ABSTRACT.}

This text presents: on the one hand, the results of an investigative exercise, which makes visible the deepest problems of the inhabitants of the communities swallows and the lighthouse of 8 commune of the city of Medellin, an exercise that be stepped forward in response to the process of institutional intervention arising from the constant processes of transformation of the city, which have led to displacement and rests with the same realities of those communities; on the other hand, it presents the proposal of solution built from the same communities face these problems.

\section{KEY WORDS.}

Territory, Urban Transformation; Development; Violence; Dignity, and Rights.

\footnotetext{
${ }^{1}$ Sociólogo Universidad de Antioquia. Investigador comunitario, integrante de la Mesa Inter-barrial de desconectados. Líder comunitario, Mesa de vivienda y servicios públicos domiciliarios Comuna 8. Medellín, Colombia. Contacto: velasquezkarlos@gmail.com
} 


\section{Introducción.}

Este proceso de acompañamiento a la comunidad de Golondrinas y El Faro nace a partir de la iniciativa de varios líderes de la parte alta del barrio que estaban preocupados por la posible construcción de un tanque de almacenamiento de agua de EPM que podría generar algún tipo de desplazamiento forzado de la población y la preocupación por la aplicación del Plan Maestro de Bordes de la EDU, donde se tenían muchas dudas frente a las implicaciones que éste proyecto tuviera en la comunidad.

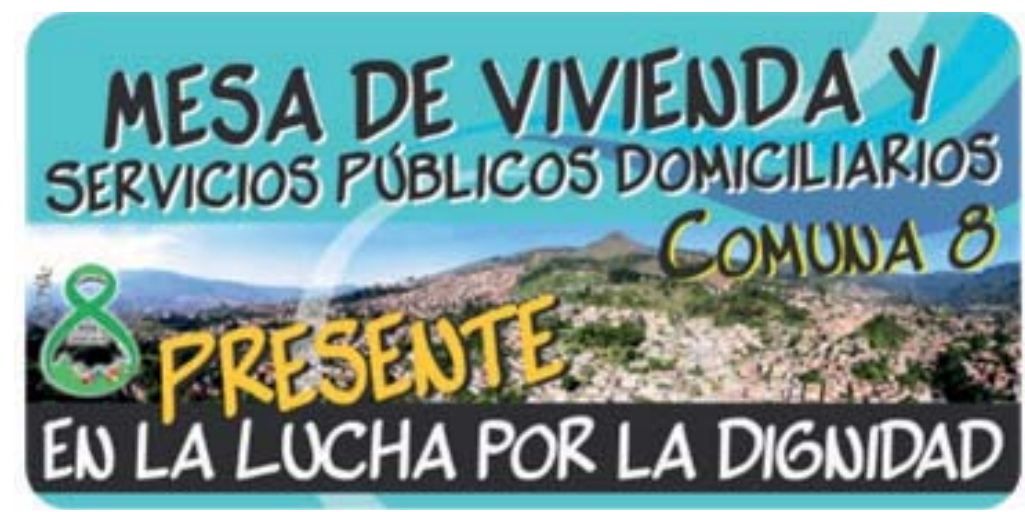

Es así que empezaron a participar de escenarios de comuna como el Encuentro por Vivienda y Hábitat de la Comuna 8 (24 septiembre 2011), el Encuentro de representantes de mesas (9 octubre de 2011) y el taller sobre exigibilidad de derechos (15 de octubre de 2011), donde con insistencia se planteaba las necesidades del sector y se solicitaba la presencia para que se pudiera asesorar a la comunidad. De ahí se definió ir al barrio a ver qué pasaba, se empezó con las primeras reuniones a partir del mes de octubre de 2011 y a realizar derechos de petición, luego el trabajo se fue notando y se empezó a generar dinámica organizativa. Al principio el acompañamiento se prestó desde algunos líderes de la Mesa de Vivienda y Servicios Públicos Domiciliarios de la comuna 8 y el Plan de Desarrollo Local, y luego en 2012 se fue acercando la Mesa de Desplazados, donde en estos momentos se trabaja de una forma articulada.

En el 2012 Golondrinas y El Faro dio sus primeros pasos como proceso organizativo y muestra de ello es que tuvo una gran participación de la población en el marco de la formulación del Plan de Desarrollo de Medellín PDM 2012-2015. A pesar de que sus propuestas no fueron escuchadas por la Administración, fue de los barrios que más se movilizó en la sesión descentralizada del Concejo en el ITM el 15 de mayo y en la Toma pacífica al Concejo de Medellin el 30 de mayo. La respuesta de la Administración es que las intenvenciones que plantea la comunidad valen mucho dinero y no alcanzan a ser cubiertas con el presupuesto ordinario e incluso algunos de los corporados fueron capaz de criminalizar la protesta haciendo alución a la posible infiltración de actores armados.

Es por eso que nos vimos en la necesidad de seguir los pasos en la construcción de una propuesta de solución a nuestras problemáticas, y en esa medida es que surge la idea de elaborar este texto que servira como insumo para ejercicio de debate político y movilización comunitaria en pro de nuestros derechos como ciudadanos y nuestra dignidad como seres humanos. Este estudio demuestra seriedad, buenos 
argumentos y calidad en su presentación, pero si la comunidad no se apropia de ellos la cuestión no avanza, esto depende de las personas del barrio y sus liderazgos, porque son los directamente afectados y los dolientes de estos proyectos de intervención.

Desde las mesas de trabajo de la comuna 8 se les asesora a las comunidades para que solucionen sus necesidades más apremiantes, a que aprendan a organizarse $\mathrm{y}$ a exigir, a donde ir a pedir x o y información o dónde gestionar. La comunidad tiene que organizarse bajo cualquier forma, llamese Junta de Vivienda o nueva JAC, pero el caso es estar organizados. Tenemos que luchar por todos, pelear y dar argumentos de forma colectiva, porque si lo hacemos individualmnete no logramos nada. También debemos tener en cuenta que no nos van a otorgar todo lo que exijamos, debemos estar muy organizados y presionando al gobierno para que nos den lo que nos merecemos.

\section{Metodologia.}

La recolección de información se realizó en diez meses, a partir de la primera reunión con la comunidad en el mes de octubre de 2011 hasta julio de 2012 . Para su elaboración se sistematizó la información recogida en 11 reuniones con la comunidad de este barrio, la mayoria de ellas realizadas en la conocida "Cancha de Tavo" y otras en la "Casa de Pinguro", uno de los integrantes del proceso. En las reuniones se contó con buena participación de la gente, incluso a algunas asistieron más de 80 personas.

Foto 1: Reunión de coordinación metodológica comunitaria.

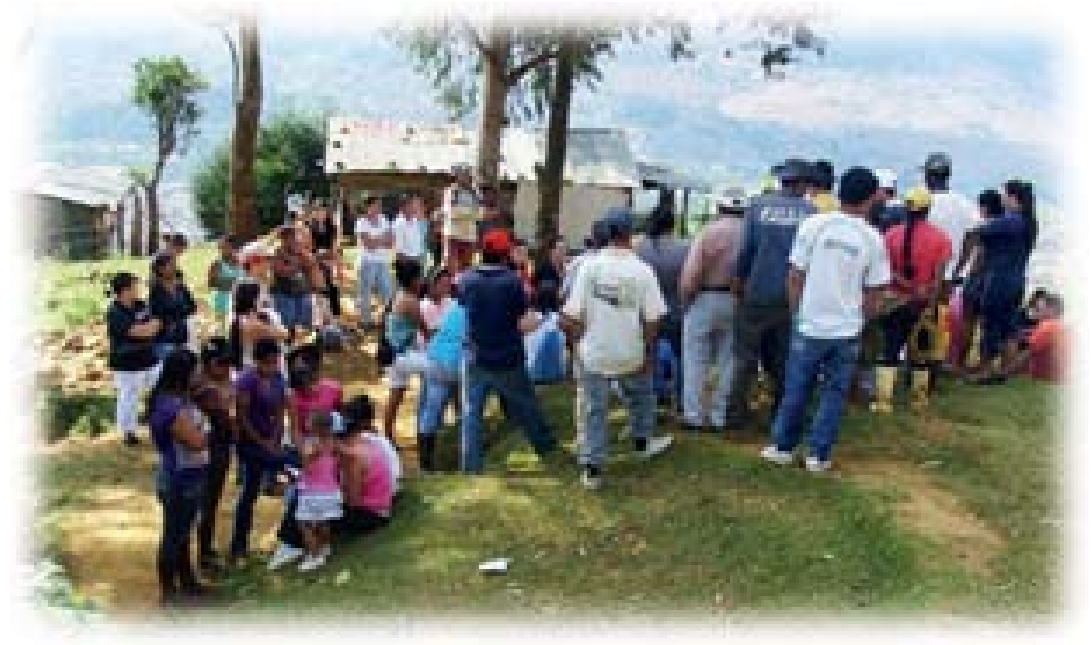

Fuente: Propia.

Igualmente se hicieron dos recorridos territoriales con mapa en mano para identificar el perimetro urbano y la cantidad de viviendas por "fuera de la ciudad", uno más enfocada a la parte rural del barrio, y otro, a la parte urbana donde está más consolidado el asentamiento. Además se tomaron fotografias de las viviendas y sus ocupantes identificando la calidad de las mismas, la situación en cuanto a servicios públicos domiciliarios, vías de acceso, espacio público y equipamientos. 
En el mes de noviembre de 2011 se realizó una encuesta a 55 viviendas pertenecientes al sector El Faro, es decir los que están por fuera del perimetro urbano, siendo una muestra representativa del $20 \%$ del total, que oscila entre las 350 y 400 viviendas. Posteriormente se realizó el proceso de tabulación y graficación, y en uno de los talleres se analizaron los resultados conjuntamente con los participantes.

Así mismo, se recogió información de segunda mano correspondiente en su mayoría a datos cuantitativos sobre el barrio, tomados de la Encuesta del Sisbén de junio de 2010 (siendo lo más actualizado), además de información sobre el Plan Maestro de Bordes realizado por la EDU en 2009 y 2010. Igualmente de derechos de petición presentados a finales del 2011 a la Unidad de Asentamientos en Desarrollo de Planeación Municipal, la EDU y EPM sobre los proyectos e intervenciones realizadas o a realizarse en el barrio.

Después de recogida y recopilada toda la información, de transcribir algunos audios, de organizar las actas de las reuniones, se procedió a organizarla para emprender el camino de la redacción final, que es el fruto que se entrega a la comunidad en el mes de noviembre de 2013, con el fin de los habitantes del territorio, puedan reconocerse en ella y puedan emprender el camino para la gestión política y social de las propuestas construidas conjuntamente.

\section{Resultados - discusiones.}

Mapa 1. Vivienda y hábitat en la comuna 8

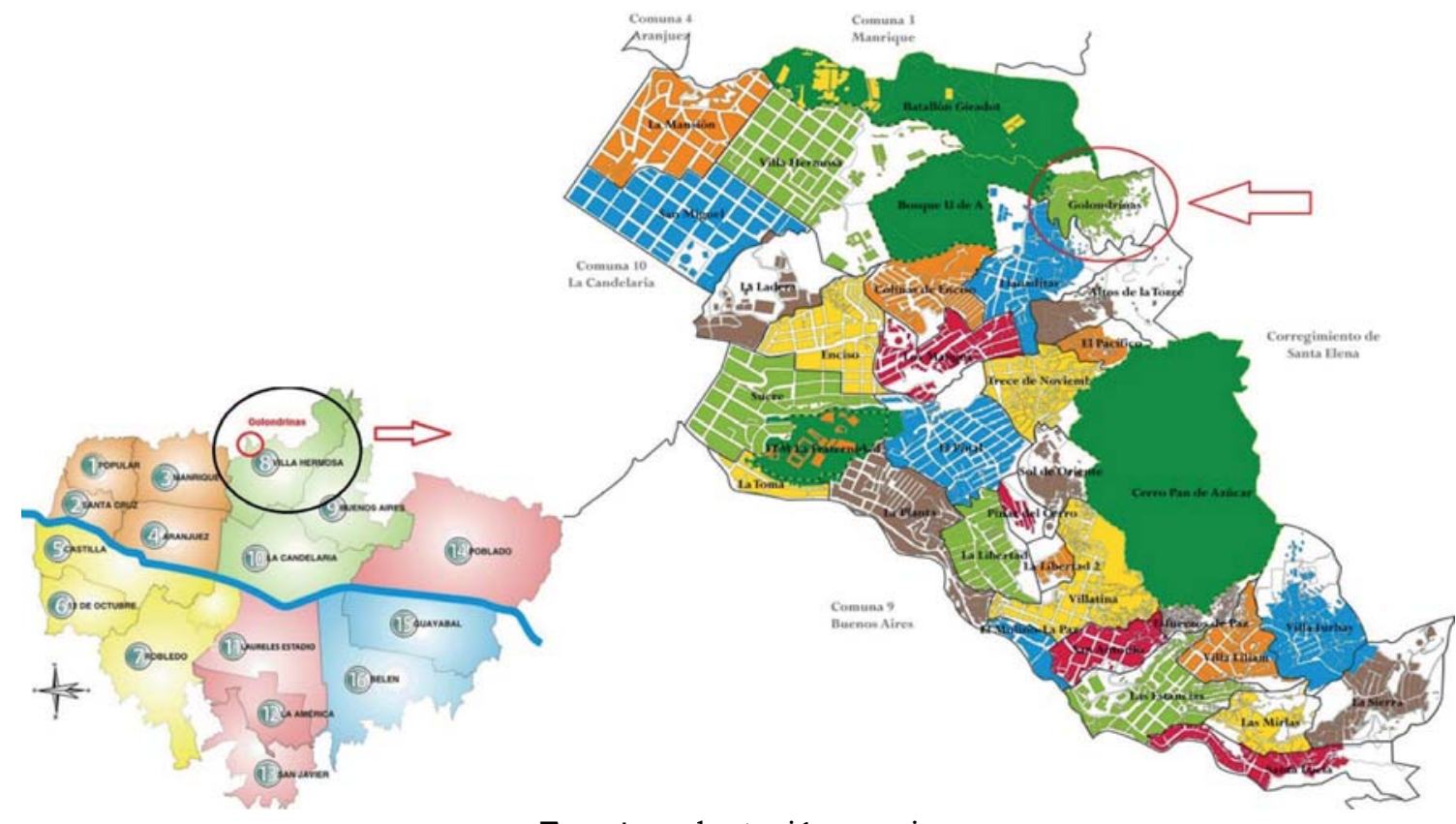

Fuente: adaptación propia 
La Comuna 8 tiene 155.354 personas que viven en 35.834 viviendas agrupadas así:

Tabla 1: Estrato.

\begin{tabular}{|c|c|c|}
\hline Estrato 1 & 14.994 & $42 \%$ \\
\hline Estrato 2 & 14.533 & $41 \%$ \\
\hline Estrato 3 & 6.287 & $17 \%$ \\
\hline Estrato 4 & 20 & $0 \%$ \\
\hline
\end{tabular}

Fuente: Propia.

Esto nos muestra un promedio de 4.3 personas por hogar, con la claridad de que en las partes altas el hacinamiento es más critico y existen hogares muy numerosos donde pueden convivir muchas familias, lo mismo sucede en el caso de los "inquilinatos" sobre todo de los barrios un poco más establecidos como Villa Hermosa.

El problema general de vivienda en la comuna 8 se presenta por el alto déficit cuantitativo de vivienda, expresado en graves problemas de hacinamiento y la existencia de muchos hogares sin vivienda propia. Igualmente existe un déficit cualitativo, debido a la existencia de viviendas inadecuadas para una vida digna, por la falta de servicios públicos, los materiales de construcción y la ubicación en zonas de alto riesgo.

En la comuna 8 existen 36.785 hogares y 46.742 núcleos familiares. Si comparamos la cantidad de viviendas y hogares nos arroja que hay un déficit de aproximadamente 1.000 viviendas, pero si lo hacemos con los núcleos familiares se deduce que hacen falta 10.000 viviendas más en la comuna 8 . Y según el ISVIMED el déficit habitacional de nuestra comuna es de 8.000 viviendas.

Se encuentran aproximadamente 3.500 viviendas en riesgo, a las que habría que generarse soluciones habitacionales de manera prioritaria, ya sea para mejorar las condiciones de estabilidad del suelo y su vivienda o para un posible reasentamiento que sea en el mismo territorio.

Tabla 2: Estado de la Vivienda

\begin{tabular}{|l|c|}
\hline $\begin{array}{l}\text { Viviendas en riesgo de } \\
\text { deslizamiento }\end{array}$ & 2.944 \\
\hline Viviendas en riesgo de inundación & 309 \\
\hline Viviendas en riesgo de avalancha & 187 \\
\hline Total & 3.440 \\
\hline
\end{tabular}

Fuente: Propia

Existen 3.200 viviendas con paredes de tabla, 1.116 viviendas con piso de tierra y 1.075 con piso de madera. Estos ranchos deben entrar en un programa de Mejoramiento Integral de Vivienda, donde se propone que aproximadamente 5.000 viviendas deben ingresar en él. En términos de la tenencia de la Vivienda en la Comuna tenemos que: 
Tabla 3: Estado de la propiedad o tenencia de la Vivienda.

\begin{tabular}{|c|c|}
\hline En Arriendo & 16.520 \\
\hline Pagando Casa & 1.607 \\
\hline Propia & 14.633 \\
\hline Otra & 4.025 \\
\hline
\end{tabular}

Fuente: Propia.

Es preocupante la situación de que casi la mitad (46\%) de los hogares esté pagando arriendo, porque implicaría que habria que plantearse una propuesta para la adquisición de viviendas para estas familias. Como se puede ir concluyendo la problemática de vivienda es una cuestión complicada que tienen muchas aristas y por lo tanto deben contemplarse y generarse soluciones a cada una de ellas, claro está teniendo un orden de prioridad por los casos más extremos o de mayor riesgo.

En cuanto a los servicios públicos domiciliarios, en la comuna 8 se evidencia la falta de cobertura de sistemas de acueducto y alcantarillado en las zonas precarias, y la desconexión de miles de hogares de los servicios de agua y energía por falta de pago, debido a las altas tarifas impuestas por EPM y las dificiles condiciones socioeconómicas de las familias con altos niveles de desempleo e informalidad.

Tabla 4: Servicios Publicos de las Viviendas.

\begin{tabular}{|l|c|}
\hline Viviendas sin energía & 146 \\
\hline Viviendas sin acueducto & 1042 \\
\hline Viviendas sin alcantarillado & 2.983 \\
\hline $\begin{array}{l}\text { Viviendas sin recolección de } \\
\text { basuras }\end{array}$ & 1.662 \\
\hline
\end{tabular}

Fuente: Propia.

Así mismo se van a presentar algunos problemas con la vivienda y el hábitat relacionados con la afectación por macroproyectos urbanos como el Cinturón Verde Metropolitano y el famoso Monorriel, donde saldrán afectados muchas viviendas que tendrán que ser reubicadas para la construcción de dichas obras.

\section{Barrios Llanaditas Y Golondrinas (De Donde Surge El Faro).}

El barrio Golondrinas está ubicado en la parte alta de la comuna 8 en las faldas del cerro tutelar Pan de Azúcar; limita al norte con la quebrada La Loca, el lote del Batallón Girardot y la comuna 3, al sur con el barrio Altos de la Torre, al oriente con la vereda Piedras Blancas del corregimiento de Santa Elena y al occidente con el barrio Llanaditas. Buena parte de su territorio se encuentra por fuera del "perímetro urbano" según el POT (Plan de Ordenamiento Territorial) de Medellín, por lo tanto figura como área rural de Santa Elena. Dicha clasificación del suelo ha impedido que se puedan hacer diferentes obras de infraestructura como el arreglo de la vía principal o la construcción de un jardín infantil, y menos aún mejoramientos de vivienda. 
Golondrinas todavía no es reconocido como barrio por Planeación Municipal pues no aparece en el decreto 346 del 2.000, que es el que define la división político administrativa de la ciudad; estaría inserto dentro de lo que la Administración reconoce como Llanaditas. Sin embargo desde el Plan de Desarrollo Local de la Comuna 8 (PDL C8) si se constituye como barrio y se encuentra incluido dentro de la propuesta de nuevo mapa para la comuna. Este problema se debe a la falta de una correcta lectura del territorio por parte del Estado que no reconoce los referentes culturales de sus habitantes al momento de definir límites o alcances de la división territorial.

Mapa 2: Barrios Llanaditas, Altos de la Torre, Golondrinas. Medellin-Colombia.

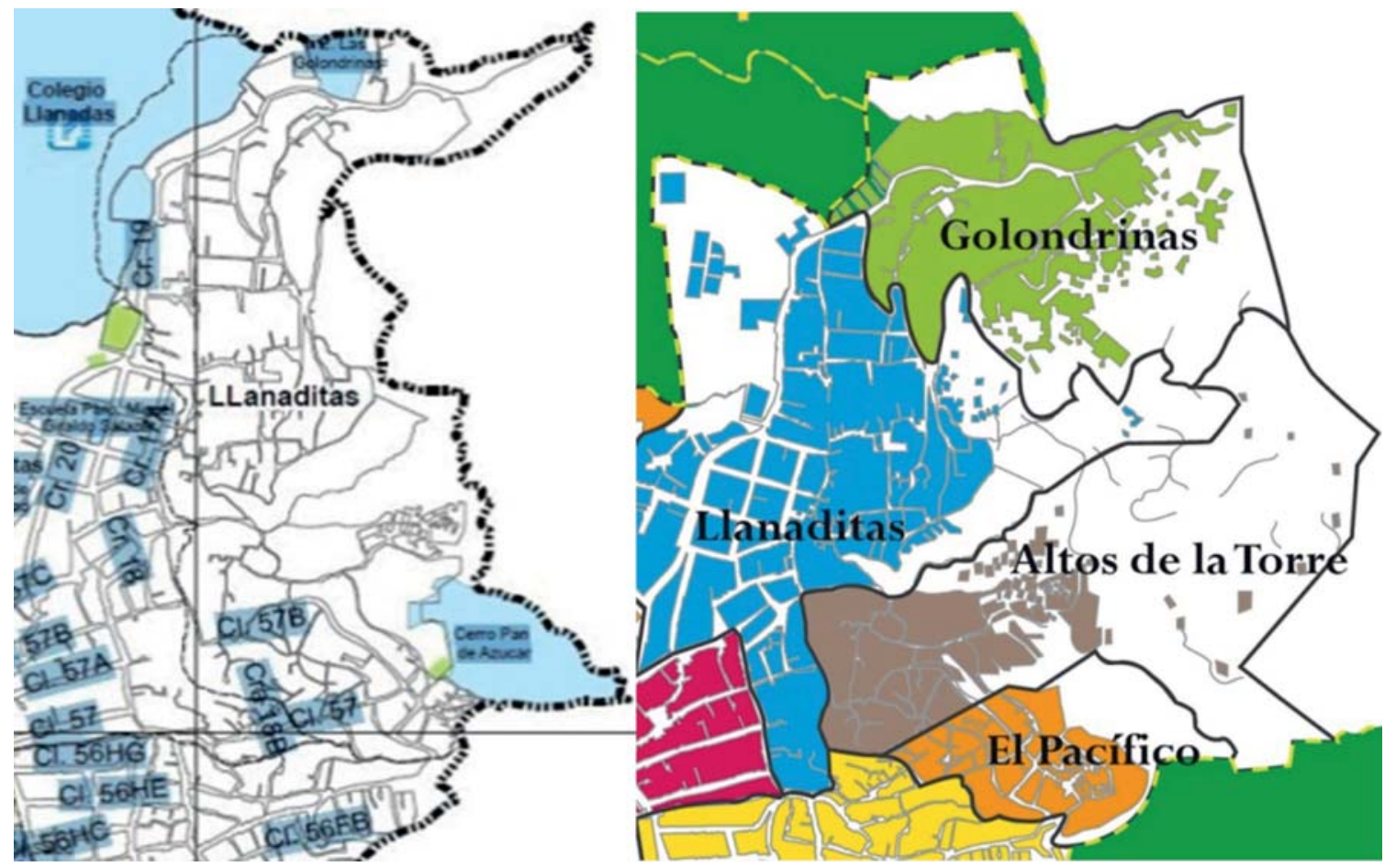

Fuente: En la izquierda Mapa de Planeación Municipal, a la derecha mapa del PDL C8.

A continuación, mostraremos algunos datos oficiales sobre la situación de la vivienda en el barrio Llanaditas según Encuesta Sisbén a junio de 2010, que comprendería todo el perimetro de los barrios Golondrinas y Altos de La Torre y parte de los barrios Llanaditas y El Pacífico.

Para el Sisbén en este territorio habitan 14.762 personas que conforman 3.181 hogares y 4.030 núcleos familiares, que habitan en 3.131 viviendas distribuidas según el estrato de la siguiente manera: 
Tabla 5: Estrato.

\begin{tabular}{|l|r|r|}
\hline Estrato 1 & 2.589 & $83 \%$ \\
\hline Estrato 2 & 485 & $16 \%$ \\
\hline Estrato 3 & 28 & $1 \%$ \\
\hline $\begin{array}{l}\mathrm{T} \mathrm{o} \mathrm{t} \mathrm{a} \mathrm{1} \\
\text { viviendas }\end{array}$ & 3.131 & $100 \%$ \\
\hline
\end{tabular}

Fuente: Propia.

El hecho de que habiten un promedio de 4.7 personas por vivienda nos da pistas sobre el grado de hacinamiento, que puede ser más dramático cuando se reconstruye el déficit cuantitativo de vivienda, que a nivel de hogares representa un déficit habitacional de 50 viviendas, pero si se hace por núcleos familiares, harian falta 899 viviendas en lo que la Alcaldía reconoce como Llanaditas. Respecto al déficit cualitativo, es decir la calidad de las viviendas, encontramos que:

Tabla 6: Material de la Vivienda.

\begin{tabular}{|l|r|r|}
\hline \multicolumn{2}{|c|}{ MATERIAL DE LAS PAREDES Llanaditas } \\
\hline Ladrillo o Bloque & 1.887 & $60 \%$ \\
\hline Madera Burda & 905 & $29 \%$ \\
\hline Tapia o Adobe & 293 & $9 \%$ \\
\hline Zinc, cartón y latas & 25 & $1 \%$ \\
\hline Bahareque & 17 & $1 \%$ \\
\hline TOTAL & 3.131 & $100 \%$ \\
\hline
\end{tabular}

Fuente: Propia

Tabla 6: Material de los Pisos LLanaditas.

\begin{tabular}{|l|r|r|}
\hline \multicolumn{2}{|c|}{ MATERIAL DE LOS PISOS Llanaditas } \\
\hline Cemento & 2.033 & $65 \%$ \\
\hline Baldosa & 468 & $15 \%$ \\
\hline Tierra & 370 & $12 \%$ \\
\hline Madera burda & 259 & $8 \%$ \\
\hline TOTAL & 3.131 & $100 \%$ \\
\hline
\end{tabular}

Fuente: Propia 
Tabla 7: acceso a servicios públicos domiciliarios.

\begin{tabular}{|l|l|}
\hline \multicolumn{2}{|c|}{$\begin{array}{c}\text { ACCESO A SERVICIOS PÚBLICOS } \\
\text { DOMICILIARIOS Llanaditas }\end{array}$} \\
\hline Hogares sin conexión a Acueducto & 193 \\
\hline Hogares sin conexión a Alcantarillado & 596 \\
\hline Hogares sin Recolección de Basuras & 295 \\
\hline Hogares sin línea de Teléfono & 1.348 \\
\hline Hogares sin Gas Domiciliario & 3.122 \\
\hline
\end{tabular}

Fuente: Propia

Tabla 8: Viviendas en Riesgo, Llanaditas.

\begin{tabular}{|l|l|l|}
\hline \multicolumn{3}{|l|}{ VIVIENDAS EN RIESGO Llanaditas } \\
\hline Deslizamiento & 784 & $25 \%$ \\
\hline Inundación & 26 & $1 \%$ \\
\hline Avalancha & 27 & $1 \%$ \\
\hline Otros & 7 & $0.5 \%$ \\
\hline TOTAL & 844 & $27.5 \%$ \\
\hline
\end{tabular}

Fuente: Propia

Barrio el Faro.

Ahora queremos dar cuenta de la realidad de la parte alta de Golondrinas, lo que conocemos como el barrio El Faro, haciendo un análisis de las viviendas que se encuentran por fuera del perímetro urbano. El Faro podría delimitarse de la siguiente manera: de la cota 1900 a la cota 2060 (sobre el nivel del mar), y desde la quebrada La Loca hasta la quebrada Chorro Hondo, que sería el perimetro que cobijaria el nuevo barrio con la nueva JAC El Faro. Limitaría hacia el norte con Golondrinas, al occidente con Llanaditas, al sur con Altos de La Torre y al oriente con el corregimiento de Santa Elena. 
Mapa 3. Ubicación Barrio el Faro. Medellín

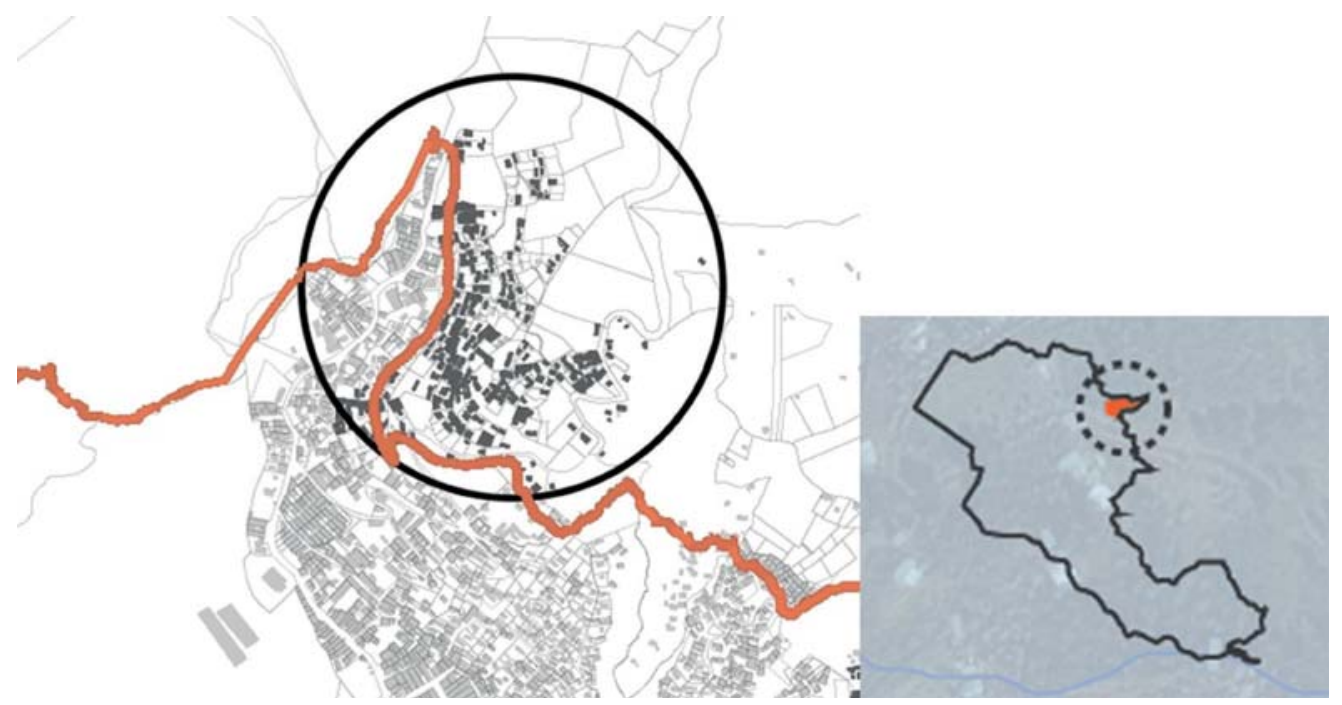

Ubicación del barrio El Faro en la comuna 8, en línea roja el perímetro urbano Fuente: Propia.

Foto 2. Ubicación Barrio el Faro. Medellín.

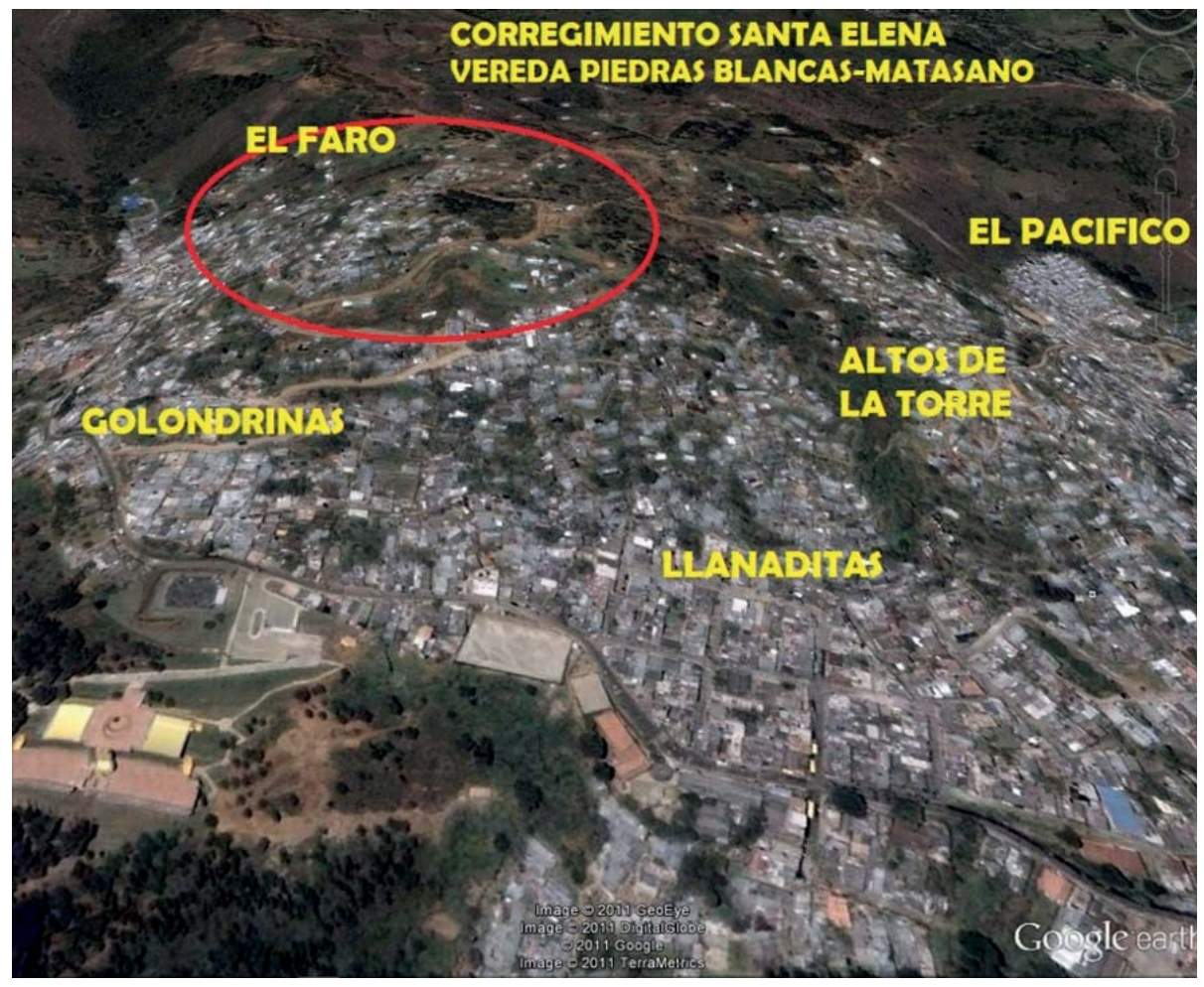

Fuente: Foto Aérea del barrio El Faro y sus límites territoriales. Google Eart 
En este territorio logró realizarse una "Encuesta Comunitaria" donde se recogieron 55 casos de un promedio de 300 viviendas ubicadas por fuera perímetro urbano, es decir que se obtuvo una muestra del $20 \%$, muy representativa que nos da cuenta de la totalidad de la comunidad. Por lo tanto los resultados que se presentan a continuación hacen parte de una proyección al total de viviendas del barrio.

Para la encuesta se destinó todo un día con participación del Equipo Técnico del PDL C8, la Mesa de Vivienda y Servicios Públicos Domiciliarios Comuna 8 y algunos miembros de la comunidad que le ayudaron a sus vecinos a llenar la ficha con un total de 20 preguntas, al lado del fogón del sancocho comunitario.

\section{Población.}

Dentro de los principales resultados encontramos que en El Faro habita Un solo hogar en el 65\% de las viviendas; Dos hogares en el 24\% viviendas y Tres hogares en $11 \%$ de las viviendas. Esto quiere decir que en las 300 viviendas aproximadamente, pueden estar habitando unos 440 hogares y que se tendrian que generar 100 viviendas como mínimo, ya que estas familias se encuentran en hacinamiento, se encuentran muchos casos que son madres cabeza de familia jóvenes que viven con uno o dos hijos, pues como dicen ellas "el marido no quiso responder".

Gráfica 1. Hogares por vivienda

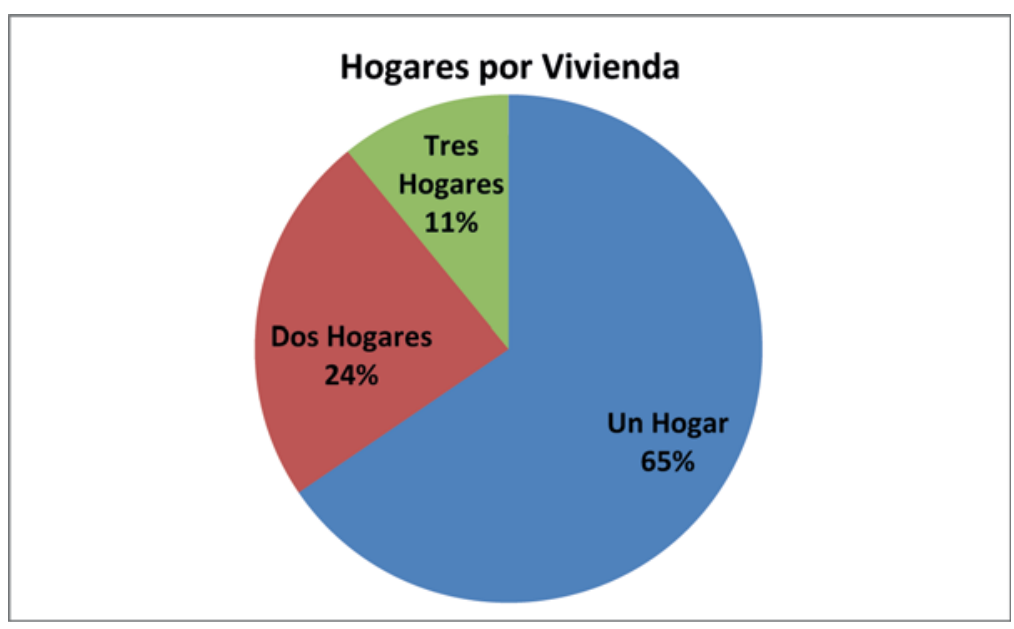

Fuente: propia.

La encuesta también nos determinó que existe un promedio de 5 habitantes por hogar, que multiplicado por 300, no da un aproximado de 1.500 personas que se encuentra por fuera de la linea urbana. Ahora bien hay que tener cuidado a la hora de hacer los análisis, y de otorgar posible soluciones habitacionales, ya que si bien un $42 \%$ son familias compuestas por tres o cuatro personas, también se encuentra un $5 \%$ de los hogares son personas solas, en su mayoría personas de la tercera edad, y en muchos casos en situación de discapacidad. Otro $7 \%$ son parejas, sean estas de una madre con su hijo/a o de esposos sin hijos. Y finalmente, y son los casos más preocupantes a la hora de un posible reasentamiento de población, en un $31 \%$ de las viviendas habitan más de 7 personas, que no cabrían en las soluciones habitacionales que otorga el municipio en la actualidad. A continuación 
la gráfica que nos muestra la distribución de acuerdo a los hogares de la muestra, que nos da un total de 289 personas:

Gráfica 2. Personas por vivienda.

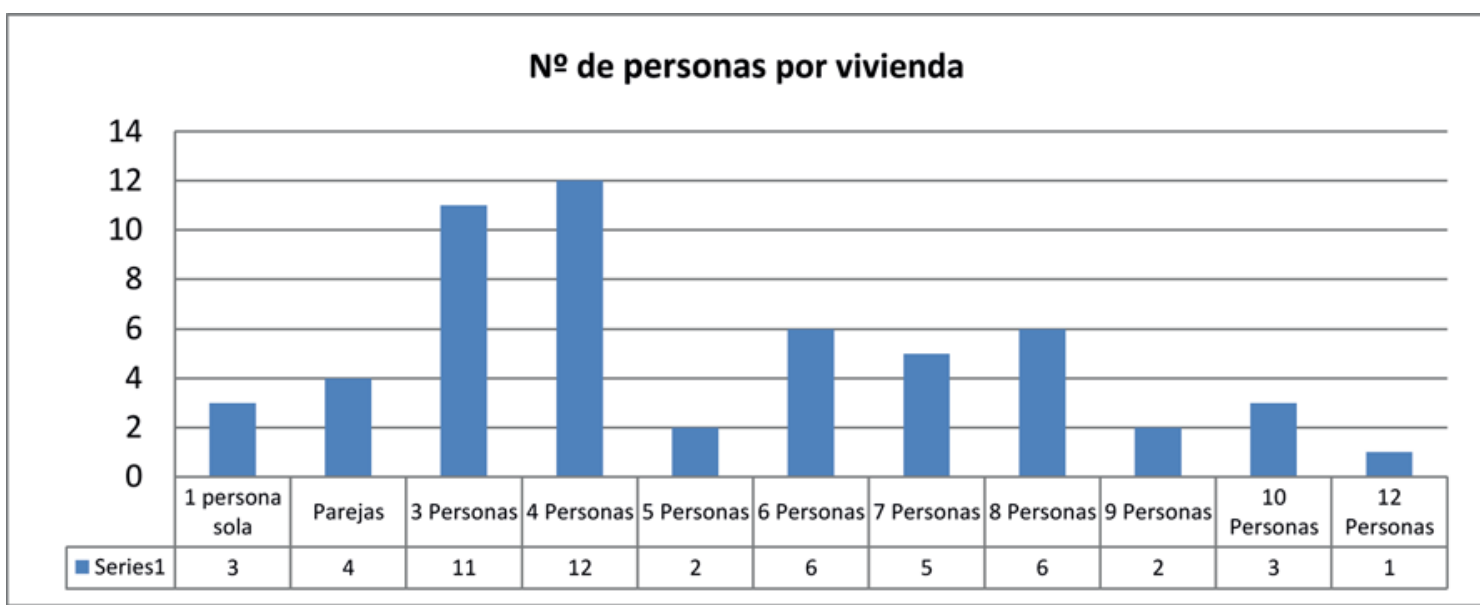

Fuente: propia.

Las edades de la población es importante analizarlas, ya que nos da cuenta del grado de vulnerabilidad en que se encuentran estas familias. Este análisis nos da que el $55 \%$ de la población debe ser atendida con especial atención pues son menores de 18 aproximadamente 705 niños y niñas y 120 adultos mayores de 60 años.

Gráfica 3. Edades de la Población.

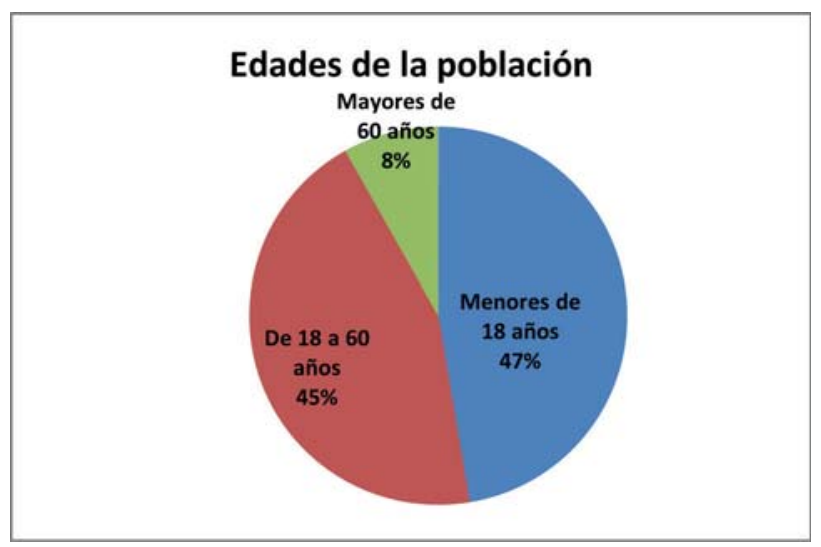

Fuente: propia.

En cuanto al grado de vulnerabilidad encontramos que el $7 \%$ de sus habitantes son personas en situación de discapacidad, es decir que pueden ser aproximadamente 105 discapacitados y que el $47 \%$ son Madres cabeza de hogar, que representan aproximadamente 141 hogares.

Otra de las características de este asentamiento y de su población que los hace aún más vulnerable es que el $84 \%$ de sus familias han sido víctimas de desplazamiento forzado, que representan unos 252 hogares aproximadamente. 
E1 82\% han sido desplazados de municipios de Antioquia, 9\% de otros departamentos y 9\% desplazados Intraurbanos. De Antioquia, un 36\% proviene de la región Norte, de municipios como de San Andrés de Cuerquia, Ituango, Yarumal, Toledo, Briceño y Valdivia. Los períodos de mayor expulsión se dieron a principios y finales de la década del 2000. En segunda instancia del Occidente con un $28 \%$, de ellos un $50 \%$ del municipio de Dabeiba, y otros como Peque, Liborina, Frontino y Uramita, cuyo periodo de mayor expulsión ocurrió entre los años 1998-2003.

Un tercer grupo importante lo constituye el Oriente con un $22 \%$, de los municipios de Granada, San Carlos y Sonsón. Los periodos de mayor expulsión se presentaron entre 1993-1995 y entre el 2.000-2003. Ya en menor medida se presentan desplazados de la región de Urabá con un 8\%, el Nordeste 3\% y Suroeste 3\%.

Los desplazados de otros departamentos provienen de Caldas, Guaviare, Cauca y Chocó. Y los Intraurbanos de barrios como Villa del Socorro en la comuna 2 y Belencito de la comuna 13, así como del barrio El Pinal en Bello, limites con la comuna 1 de Medellín. La mayor expulsión se presenta en los últimos tres años que se acentuó el conflicto urbano en el Área Metropolitana, por la disputa entre bandas paramilitares y combos delincuenciales.

$\underline{\text { Vivienda. }}$

Gráfica 4. Material de los Pisos.

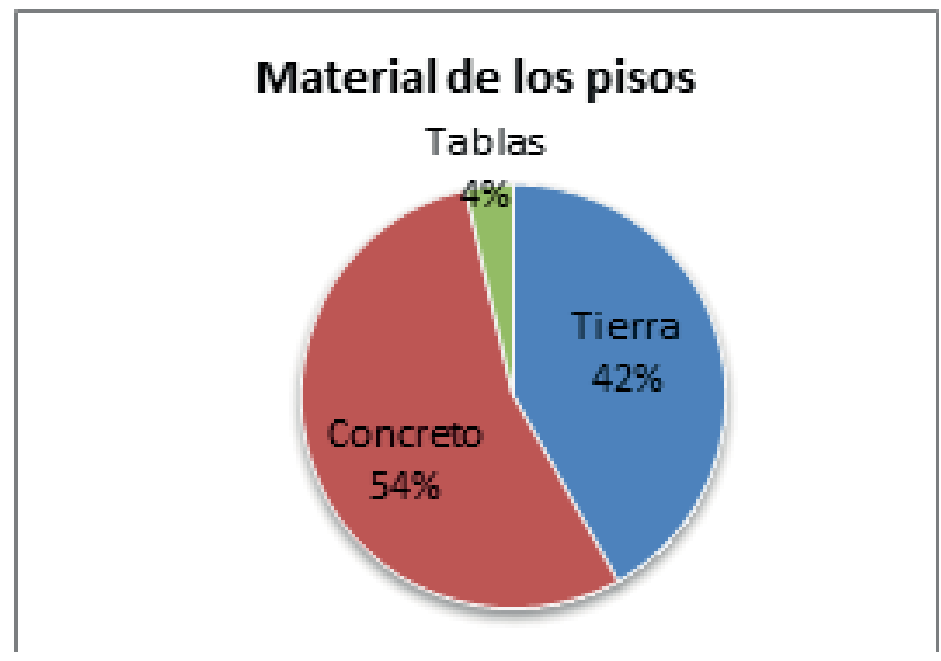

Fuente: propia.

Estas características fueron evaluadas de acuerdo al material de construcción de sus viviendas. Respecto a los pisos, unas 126 viviendas aproximadamente poseen piso de tierra, otros 162 en concreto y unas 12 en tablas, lo que nos lleva a determinar que aproximadamente la mitad de sus viviendas necesitan entrar a un programa de mejoramiento de vivienda de carácter prioritario, pues las condiciones actuales no les brinda muy buenas garantías y da cuenta de su condición de precariedad.

Por otra parte el material de las paredes nos ayuda a tener muchos más argumentos, pues solo 126 viviendas están construidas con ladrillo, 6 prefabricadas y 15 en 
bahareque (las viviendas más antiguas y que pertenecian a antiguas fincas de la zona) que representan el $49 \%$ de las casas. Mientras que el $51 \%$ pertenecen a paredes con materiales no adecuados o de deficiente calidad, pues si bien hay 132 viviendas son de tablas, éstas no son de buena calidad, y pertenecen más bien a la categoria de ranchos. E igualmente se pueden encontrar aproximadamente unos 21 ranchos cubiertos de materiales como el plástico o lona.

Gráfica 5. Material de las paredes.

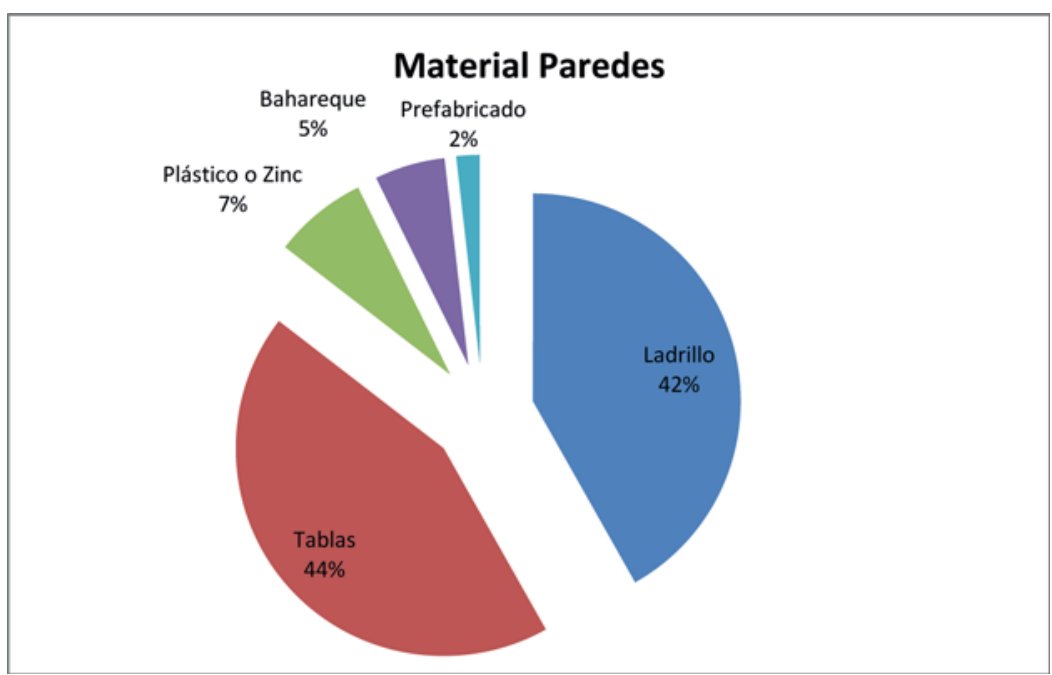

Fuente: propia.

Foto 3: Estado de las viviendas.

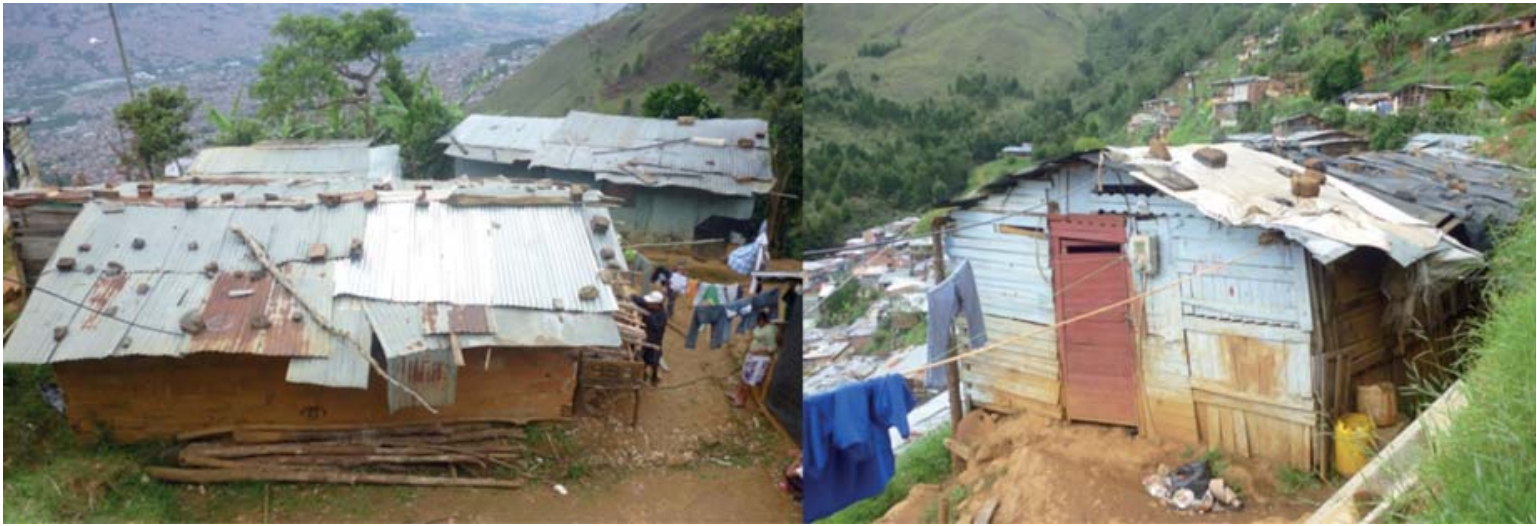

Fuente: propia.

Por otro lado la gran mayoria, casi el 70\% (unas 207 viviendas) tiene techo de zinc, siendo el material más económico que se puede encontrar en el mercado. Seguido del Eternit con 33 viviendas, plancha 21 y en plástico 39, que son los casos de mayor vulnerabilidad, pues estás expuestos a torrenciales y aguaceros muy fuertes y es constante que se les inunde sus viviendas. 
Gráfica 6. Material de los techos.

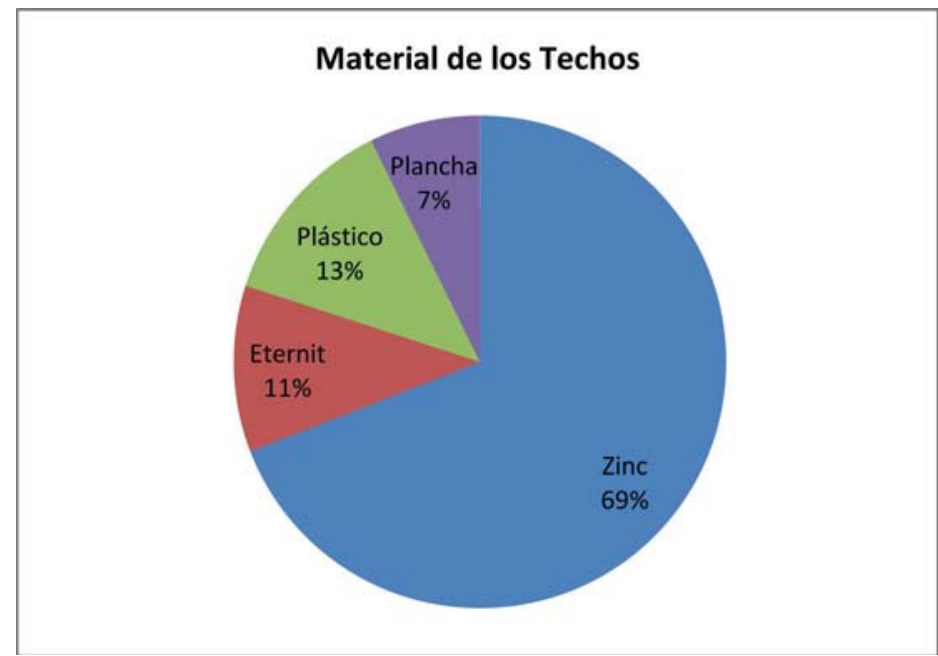

Fuente: propia.

La mayoría de las viviendas (93\%) sólo poseen un nivel, sin embargo encontramos que el $7 \%$ son viviendas de dos pisos o más. Ahora bien respecto a las habitaciones por vivienda encontramos que hay una grave situación de hacinamiento de déficit cualitativo habitacional, pues casi unas 100 viviendas, es decir 33\% de los hogares están viviendo en una sola habitación o espacio, lo que nos muestra el alto grado de hacinamiento.

Foto 4. Estado de algunas viviendas

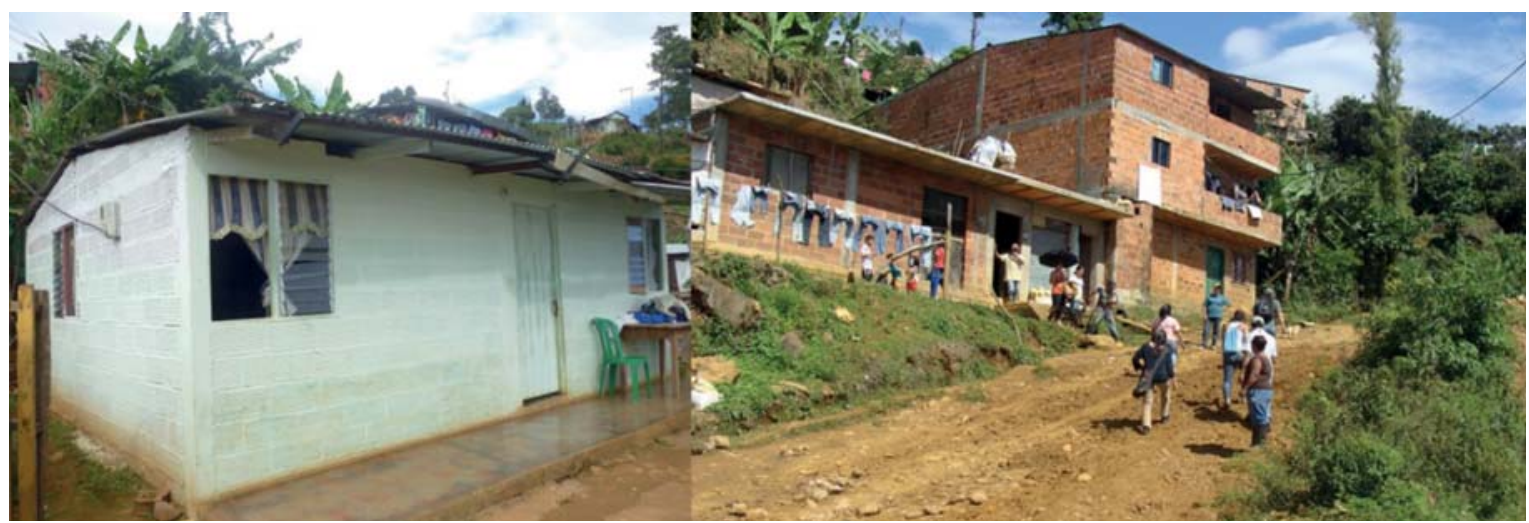

Fuente: Propia. 
Gráfica 7. Habitaciones por vivienda.

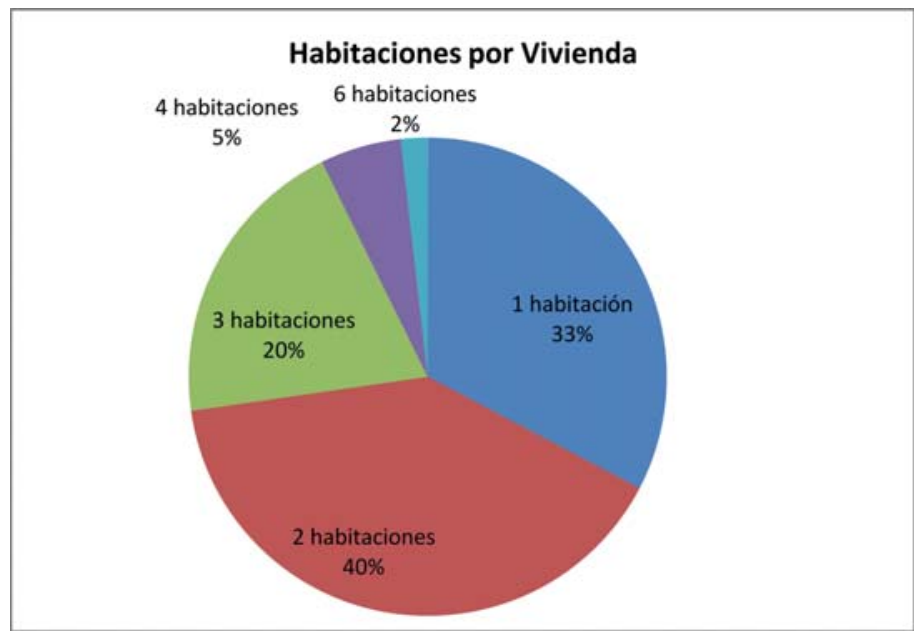

Fuente: Propia.

Aproximadamente 120 viviendas poseen 2 habitaciones (40\%), que es lo que más predomina. Pero igualmente encontramos que el 20\% son de 3 habitaciones, un 5\% de 4 habitaciones y finalmente, las casas más grandes que tienen hasta 6 habitaciones (2\%), que son las resultarian más afectadas por un posible reasentamiento, ya que las soluciones de vivienda que ofrece el gobierno sólo tienen 2 habitaciones en su mayoria, lo que las haría empeorar su situación de hacinamiento. A la hora de otorgar mejoramientos de vivienda es necesario darle prioridad a las que tienen 1 y 2 habitaciones.

Los años de mayor llegada al barrio se presentan entre el 2.000 hasta hoy con un $74 \%$. Es decir que ha sido un territorio poblado y construido esta última década. A continuación se puede observar la tabla de los años que habita la vivienda:

Tabla 9: años de estar en el Barrio.

\begin{tabular}{|l|l|}
\hline Hace 1 año & $18 \%$ \\
\hline 2 a 5 años & $24 \%$ \\
\hline 6 a 9 años & $13 \%$ \\
\hline 10 a 13 años & $26 \%$ \\
\hline 14 a 17 años & $13 \%$ \\
\hline 18 a 21 años & $6 \%$ \\
\hline
\end{tabular}

Fuente: propia.

Frente a la pregunta por la propiedad de la vivienda, a pesar de que muchos dicen que es propia, de ellas solamente 2 poseen escrituras, el resto tienen compraventa, o sea que jurídicamente entrarian dentro de la categoría de posesión, quedando los porcentajes de la siguiente manera: 
Gráfica 7. Propiedad o tenencia de la Vivienda.

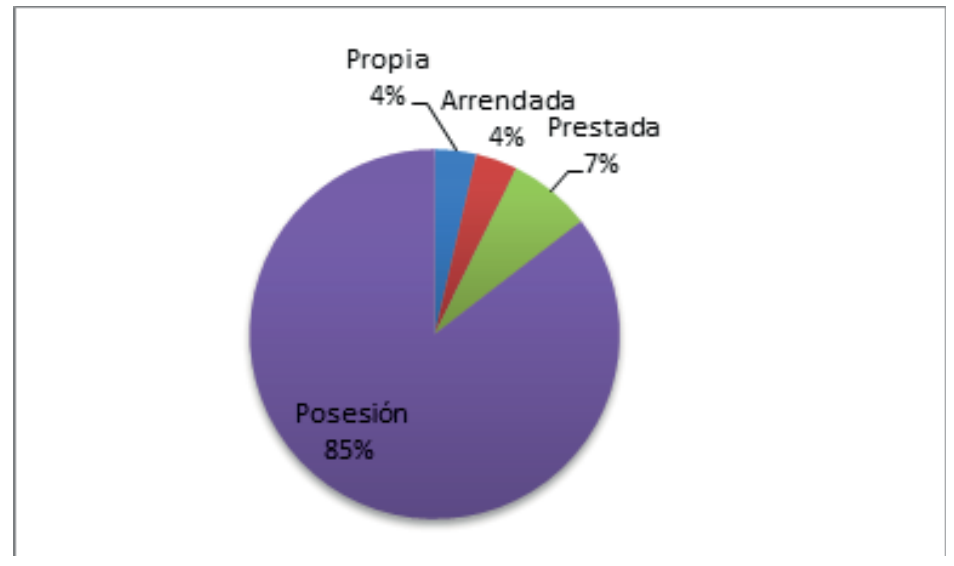

Fuente: Propia.

Ahora bien, a pesar de no tener escrituras al 69\% de las viviendas les llega el cobro del impuesto predial. Es importante tener en cuenta que el mayor porcentaje $(40 \%)$ les empezó a llegar el recibo durante la última administración municipal de Salazar, que si bien no reconoce el asentamiento si les cobra impuesto a aquellos que no tienen con qué.

Gráfica 8. ¿hace cuánto le llega el predial?.

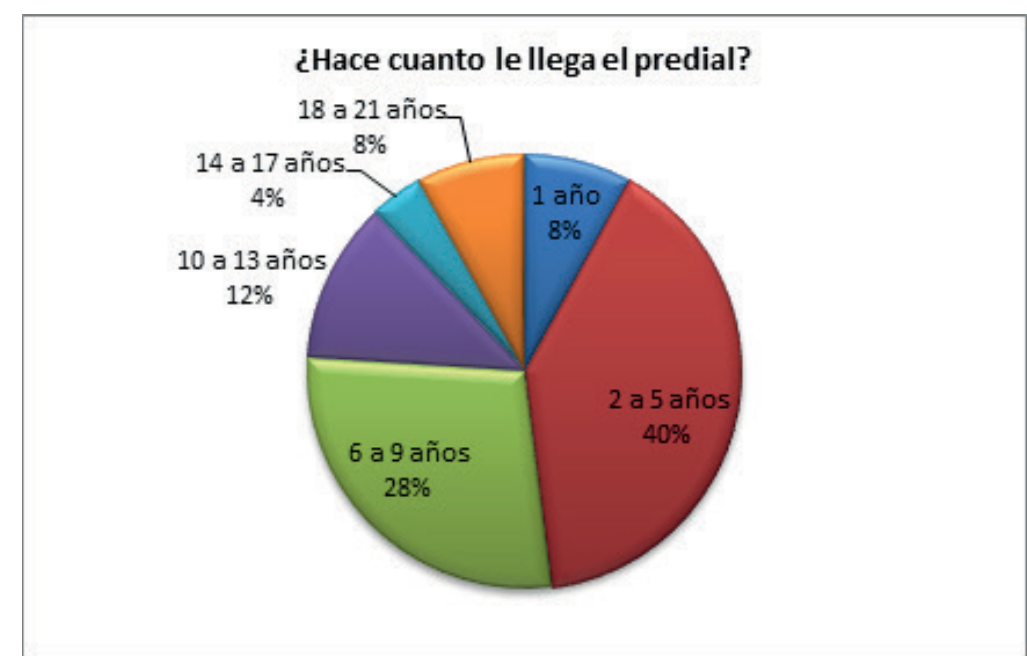

Fuente: Propia.

La principal propuesta son los mejoramientos de vivienda para el barrio que conlleven a sus habitantes a tener Viviendas dignas, la siguiente intervención resume el clamor de la comunidad: "La casa es de tabla muy malita, cuando llueve nos mojamos. Estamos muy pobres, no tenemos que comer y estamos muy mal dormidos". Otros al no tener vivienda comentan: "Quiero que nos ayuden a los que no tenemos donde vivir, que nos den una tierrita para hacer una casita para vivir con nuestros hijos y nietos, que no nos falte el agua que es la principal y la luz". Y 
finalmente algunos proponen la "Legalización de predios, es decir, darnos el papel de la escritura".

Por otro lado se presenta una problemática relacionada con los subsidios de vivienda, ya que muchos salieron del sistema porque pagan catastro. Queremos realizar esta denuncia nacional e internacional para levantar esta restricción del impuesto predial o de las personas que todavía figura su nombre en las escrituras de donde lo desplazaron. Se solicita a la Personería de Medellin para que haga una jornada de recolección de estos casos en el barrio.

\section{Servicios Públicos Domiciliarios.}

La problemática de los servicios públicos es una de las más complejas del barrio El Faro, pues no tienen acceso debido a su clasificación como suelo rural. E1 acueducto comunitario es deficiente pues no les llega agua todos los dias o tienen racionamientos durante el dia, igualmente no tiene un proceso de potabilización. Son aguas de la quebrada La Castro que son transportadas por tubos hasta un tanque de distribución en el barrio, sin embargo muchas familias consumen aguas contaminadas pues algunas personas de la parte baja y media de la comuna suben hasta la bocatoma a recrearse y bañar sus mascotas. Igualmente en el corregimiento de Santa Elena de donde proviene la quebrada se encuentran gran cantidad de marraneras y cultivos que pueden producir filtraciones al agua.

Foto 5: Acueductos comunitarios Barriales.

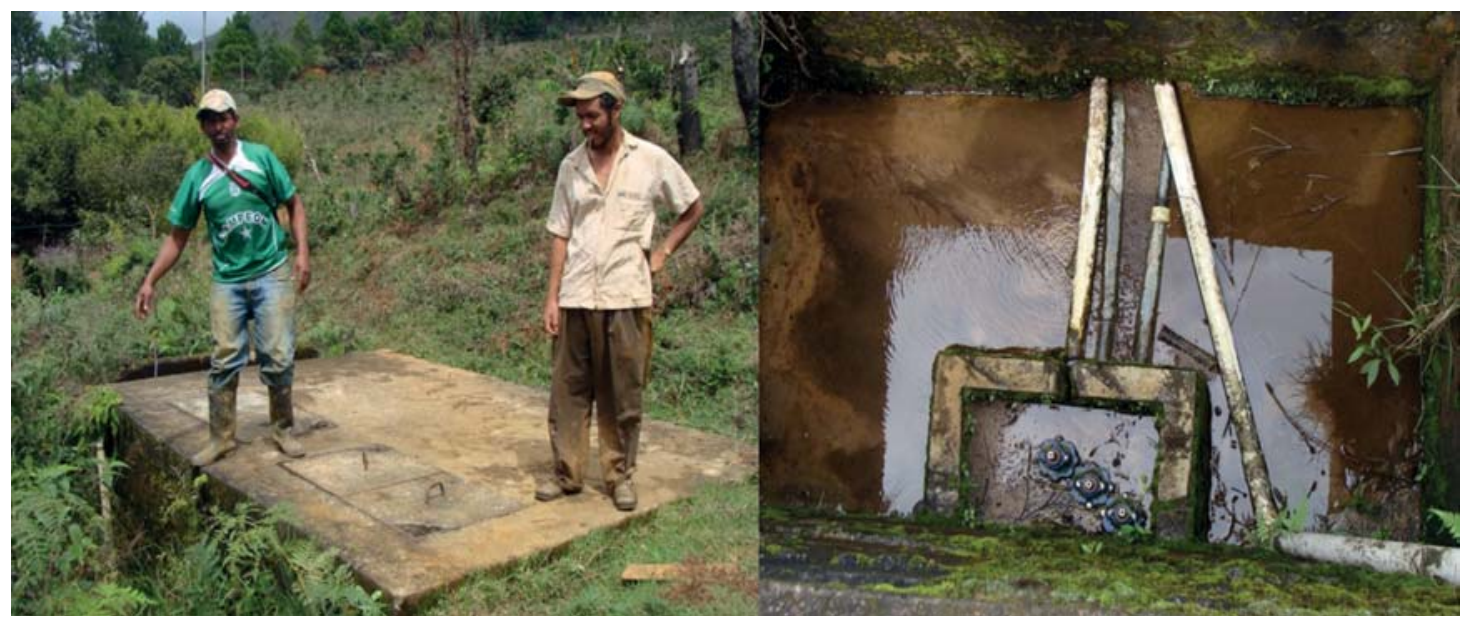

Tanque distribuidor de agua del acueducto comunitario, en la derecha se muestran las válvulas de distribución para los sectores que surte: Altos de la Torre y Pacífico, Llanaditas y Golondrinas.

Fuente: Propia.

No se cuenta con un servicio de alcantarillado, las aguas sucias y lluvias son transportadas de manera artesanal por tubos que conducen a las quebradas directamente sin ningún tipo de tratamiento. Esta situación genera no sólo riesgos de deslizamientos por las constantes filtraciones de agua en el terreno, sino también problemas de salud pública por la proliferación de bichos y zancudos, y sus habitantes están más propensos a enfermedades de la piel. 
Foto 6: recolección de agua lluvia y alcantarillado a cielo abierto.

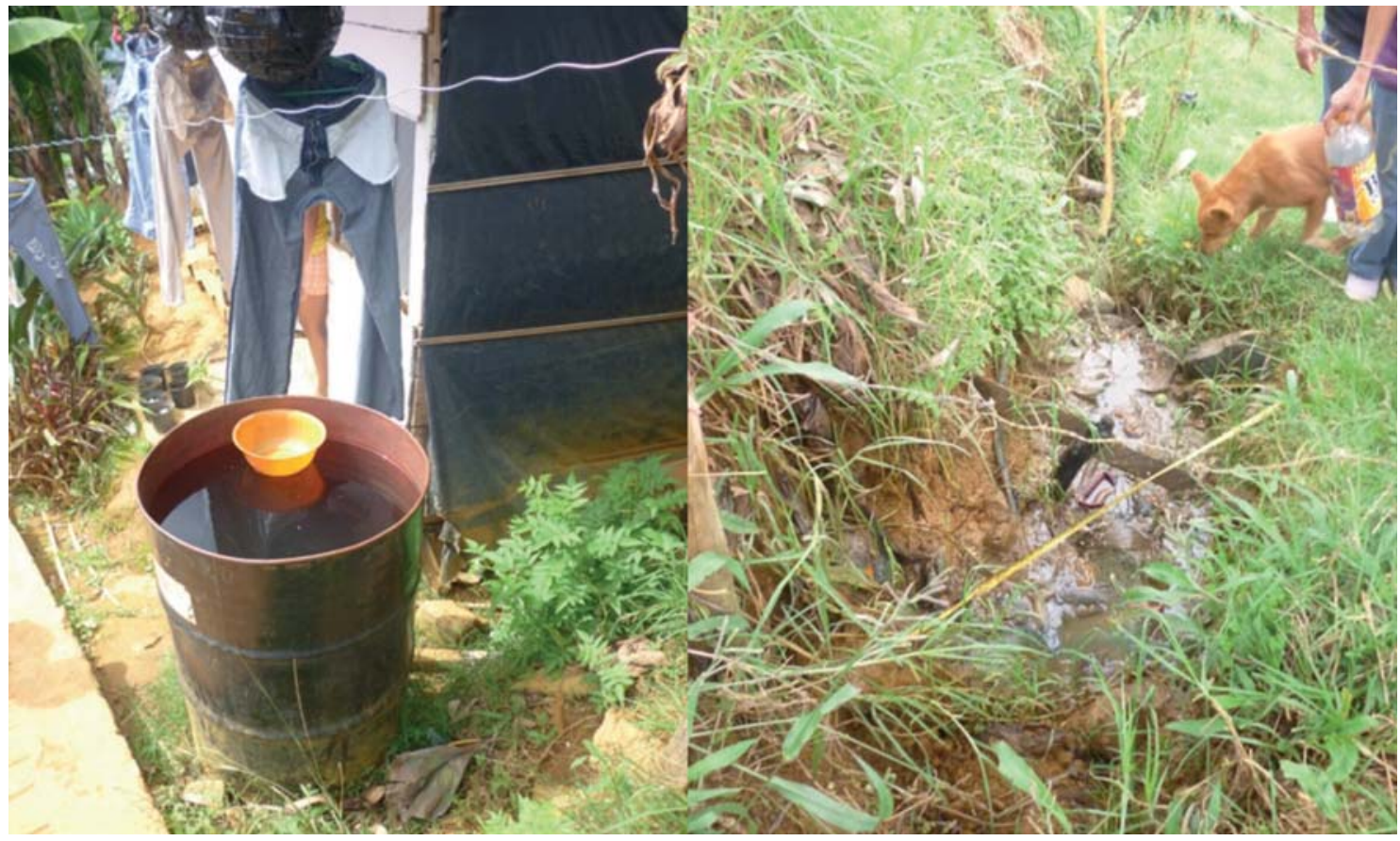

Izquierda: habitantes recogen aguas lluvias para suplir la falta de agua. Derecha: alcantarillados a cielo abierto.

Fuente: Propia.

En cuanto al servicio de energía, si bien la mayoría cuenta con su contador o con el prepago, las mayores inconformidades de la comunidad están referidas a las altas tarifas que tienen que pagar por este servicio. La telefonía es precaria, solo unos cuantos hogares cuentan con la línea y sólo hay un teléfono público en todo el asentamiento, y el factor que utiliza la empresa Une para negar el servicio es que supuestamente están ubicados en zonas de alto riesgo, sin embargo la comunidad se cuestiona cómo es posible colocar la luz pero no colocar el teléfono. Finalmente la recolección de basuras es otra de las dificultades del barrio, pues sus habitantes tienen que llevarlas a unos sitios de disposición que pueden estar a más de cuatro o cinco cuadras de distancia de sus hogares.

En Golondrinas se están adecuando las redes de acueducto y alcantarillado como parte de una obra de "mitigación del riesgo", contrato que ejecuta las EPM en convenio con las JAC del sector. Este proyecto fue luchado y ganado por las comunidades de los barrios Golondrinas, Llanaditas, Altos de La Torre y Pacífico a través de un proceso de movilización social, cuando se estaba definiendo el Plan de Desarrollo Municipal 2008-2011, donde fueron priorizados más de 10 mil millones para la construcción de dicho acueducto.

La construcción de las obras para la provisión de agua potable y la conducción de aguas residuales comenzó en enero de 2010 y actualmente se terminó su cuarta etapa y con recursos de "Jornada de Vida" se priorizaron 2.000 millones para su continuidad. Los beneficiados de este proyecto son 2.003 viviendas con 9.464 habitantes, sin embargo se debe aclarar que hoy las familias que se encuentran por 
fuera del perimetro urbano no entran dentro de los beneficiarios a pesar de tener radio de acción dentro de la JAC, y así mismo a pesar de tener las redes de acueducto todavia el agua potable no llega continuamente por falta del tanque distribuidor.

Con el proyecto de acueducto, cada JAC va a tener su propio tanque: Golondrinas, Llanaditas, Altos de la Torre y El Pacífico. Cada casa tendrá que pagar $\$ 310.000$ por la conexión a acueducto y alcantarillado, pero el problema radica para las personas en situación vulnerable que les queda difícil el pago de esta cuota, e incluso algunos vecinos afirman que al principio en las reuniones les dijeron que no les iban a cobrar. Los costos aproximados de conexión de toda la comunidad son de 620 millones de pesos, que pueden ser asumidos por la Administración Municipal, pues los habitantes no tienen los suficientes recursos económicos para hacerlo.

La propuesta de la comunidad es quedar exentos del pago por la construcción de las redes, sus habitantes son muy pobres y necesitan condonación de la deuda o que pueda ser pagado con mano de obra o una propuesta banco del tiempo. Además se le debe dar continuidad a dicho proyecto en la parte alta del barrio que no alcanzó a ser cubierto, por ejemplo todo El Faro todavía está por fuera del proyecto.

El proyecto de EPM va hasta el perimetro urbano, hasta donde llega la Torre, la propuesta de la comunidad con base en los estudios de acueducto y alcantarillado realizados en el año 2006 por la firma "Acueductos y Alcantarillado Sostenibles S.A" (A\&A S.A) para la Alcaldía de Medellín, es la extensión de redes y a la vez pedir la pavimentación de la vía (320 metros, desde donde doña Gloria, carrera 18B hasta donde don Odilio), y que las redes de distribución puedan ser de polietileno o PVC como segunda opción. Además el trazado debe realizarse por los senderos, y no por ningún lote y las personas que queden por fuera de las redes planteadas en el estudio se deberán realizar pozos sépticos o alcantarillados no convencionales.

Mapa 4. Redes de Alcantarillado faltantes.

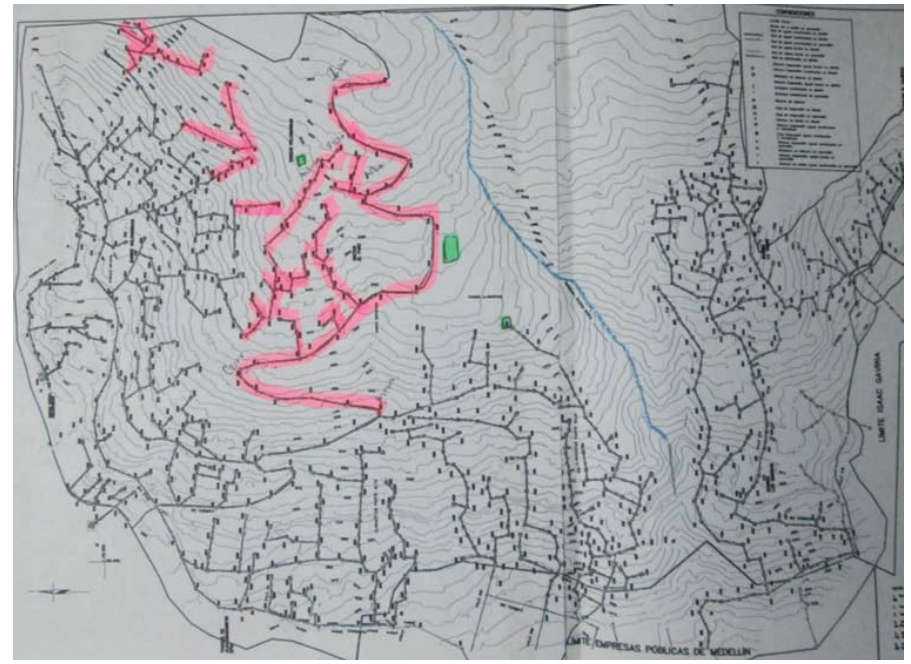

En rosado redes de alcantarillado faltante, en verde cancha de Tavo y en azul la quebrada Chorro Hondo.

Fuente: propia. 
Tal y como lo muestra el mapa anterior de A\&A S.A y el subrayado propio, hasta hoy se puede afirmar que una tercera parte del proyecto que se planteó inicialmente no se ha ejecutado. En color rosado se encuentra los territorios faltantes de redes, prácticamente todo el asentamiento El Faro. Para lograr este sueño, el estudio habla de una inversión de 2.400 millones en alcantarillado y otros 2.500 en acueducto, o sea que serian aproximadamente 5.000 millones. Así mismo exigimos los dos atenorados: de aguas lluvias y aguas sucias, que deben estar paralelos, ya que el proyecto hasta el momento solo contempla una sola red.

\section{El Tanque De Epm.}

En estos momentos las EPM tienen que construir un tanque de almacenamiento de agua para el acueducto. El problema radica en que en ningún momento le consultaron a la comunidad cuál sería el sitio más adecuado para su ubicación y donde se pretende hacerlo habitan 37 familias. No entendemos porque lo quieren hacer alli, si puede haber otros terrenos disponibles, por ejemplo, más arriba en el sitio donde está el tanque distribuidor actual. Como dice una vecina del sector: "Si ellos lo hacen donde hoy están las casas es prácticamente por sacarnos".

La cuestión es que a nosotros nos dicen que estamos en "alto riesgo", pero entonces ¿cómo piensan realizar esta obra en el barrio? Por ejemplo a doña Rosalba Quintero le llego una carta de Planeación Municipal diciéndole que su predio estaba ubicado en "suelo de protección" y que según el artículo 116 y 120 del POT corresponde a una zona de alto riesgo no recuperable. Pero ¿no es en el mismo lugar donde se pretende construir el tanque? ¿Acaso un tanque que almacenaría más de 3.000 litros de agua no pesa más que 37 viviendas? Definitivamente estamos es en zonas de "alto costo" y la Administración no lo quiere reconocer.

EPM dice que debido a que el sitio donde se construirá el tanque hoy en día figura como suelo de alto riesgo, dicha obra no se ejecutara hasta tanto no se haga la revisión del POT. Sin embargo la EDU ya lo plantea dentro de su propuesta de Cinturón Verde aún sin aprobarse el nuevo POT. Se le pregunto a EPM a través de un derecho de petición ¿Qué alternativas ofrecerá a las personas que tienen sus viviendas en el sector donde se construirá el tanque?, a lo cual dijo: "La respuesta se dará cuando definan el lugar del tanque", por lo que a nuestro modo de ver está tratando de obviar el problema.

La mayoria de gente donde se piensan construir el tanque lleva viviendo entre 15 y 18 años allí, las primeras casas fueron la de don Víctor y doña Virgelina. Nadie tiene escrituras, tienen compraventa por sus viviendas y a casi todos les llega el impuesto predial. Las EPM han medido y fotografiado los predios que "indemnizarian", esto con el fin de no pagar las mejoras que se hagan las viviendas hasta el momento del posible desalojo. Los habitantes manifiestan que: "Una cosa que nos parece maluca es que a las personas no les han dicho si quieren o no que se construyan los tanques en ese sitio, entonces es casi como una obligación".

Se exige que haya más claridad por parte de EPM acerca del tanque que van a construir. La comunidad propone un punto en la parte alta donde no afecte a las 37 familias, que es el lote de don Ovidio, donde ya se hicieron los estudios y el propietario está dispuesto a vender. La otra ventaja es que está cerca de la quebrada y esa puede recibir el agua del rebose. La propuesta para el POT es que el tanque se 
haga en la parte de arriba. Esto lo planteamos en base en el análisis de los estudios de acueducto y alcantarillado realizados por la firma "Acueductos y Alcantarillado Sostenibles S.A" del año 2006 donde presentan dos propuestas de lotes.

\section{Perimetro urbano.}

Foto 5: perimetro urbano del sector.

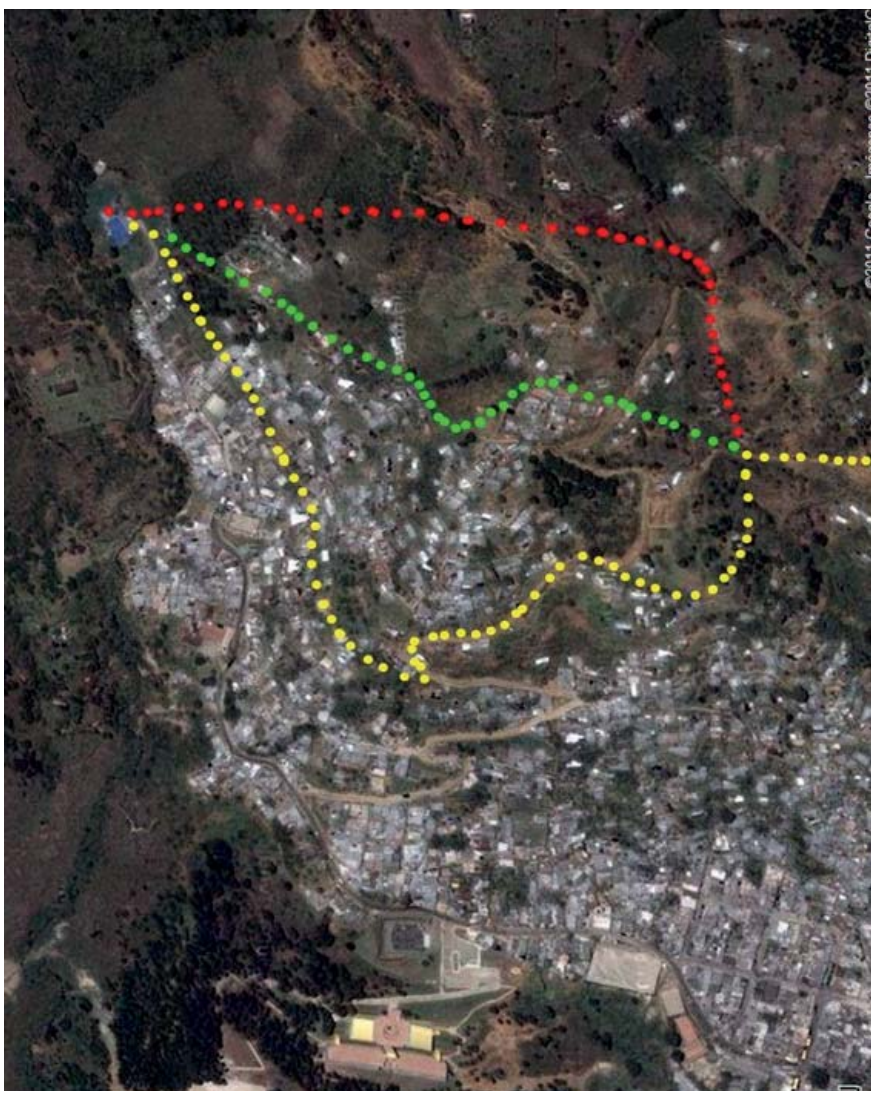

Fuente: Propia adaptación Google Eart, datos de Planeación Mucipal.

Esta es la gran pelea con el POT. En esta foto área encontramos en color amarillo el perímetro urbano definido por el POT, y en punteado color verde hasta donde se encuentran viviendas juntas, es decir, hasta donde está urbanizado y en rojo otra posibilidad de ampliación del perímetro teniendo en cuenta la construcción de tanque de agua un poco más alto que lo que se tiene planeado.

Según esta linea amarilla, mucha parte del barrio pertenece a Santa Elena. Son aproximadamente 350 viviendas ubicadas por fuera del perimetro, y de ellas unas 60 viviendas que están más en la parte rural y son como finquitas, pues muchas poseen parcelas y huertas caseras. Son más de 130 viviendas hacia Golondrinas (cuenca de la Quebrada La Loca) y más de 170 en El Faro propiamente dicho, compuesto por los sectores El Tanque, La Torre y Cancha de Tavo.

Desde el PDL está una propuesta de nuevo mapa y nueva división político administrativa para la comuna, donde se propone separar los sectores de Llanaditas 
y quedar como: Golondrinas, Altos de La Torre y El Pacífico, sin embrago hay que reformularlo para aparezca también el barrio El Faro. Para ello es necesario la revisión y cambio del acuerdo municipal 346 del 2.000, pero que a su vez que El Faro ingrese al perimetro urbano dentro en la revisión del POT.

En el 2014 se revisa el POT, por eso es muy importante incidir allí, porque este instrumento de ordenamiento territorial es el que define que nosotros estamos en zona de riesgo y en suelo rural (Santa Elena), y es bien importante que nos movilicemos frente a esto. Primero que el barrio sea reconocido como Golondrinas y El Faro; dos, que las casas de la parte alta entren a pertenecer a zona urbana, se necesita ampliar el perimetro urbano de la cota 2.000 como está actualmente, hasta la cota 2.060 en cercanias a la estatua de "Mas Bosques" que delimitaba la zona urbano rural, por la casa de Iván Pinguro.

Actualmente El Faro está clasificado como suelo de protección, se necesita cambiar el uso del suelo a urbano, porque con dicho argumento es que no nos dan mejoramientos, ni alcantarillados, por eso es que no construyen la carretera. Si no hacemos el cambio este año, nos tocará esperar 8 o 12 años (cuando se haga la revisión de mediano y largo plazo del POT) para que se cambie este uso actual. Por eso la importancia de movilizarnos organizadamente, ya que el POT que se revisara esta vez tendra una vigencia para tres periodos de alcaldía y si no logramos desafectar estos terrenos, no vamos a tener ningún tipo de obras en el barrio en mucho tiempo.

Zonas De Alto Riesgo.

Mapa 6. Zonas de Alto Riesgo.

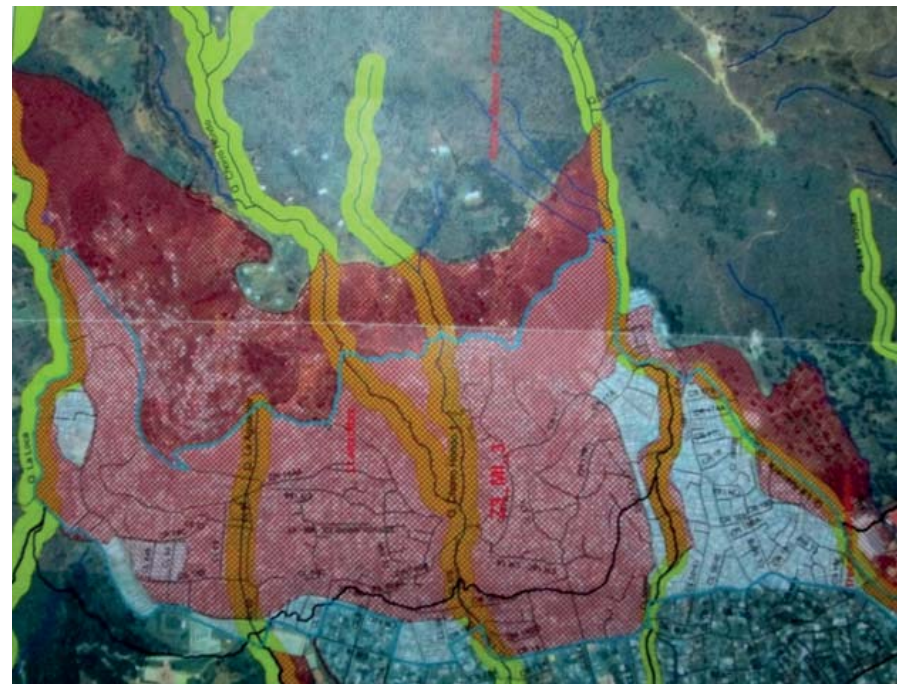

Fuente: Mapa Zonas de Alto Riesgo según POT, polígono Z3_MI_3

El POT dice que todo el barrio Golondrinas y El Faro se encuentran en ZAR (zona de alto riesgo), el mapa que nos afecta fue hecho en 1999 y modificado en 2006. Pero la Universidad Nacional sede Medellín realizó un estudio hace tres años, presentando un nuevo mapa de riesgos para la comuna, donde dice que hay zonas donde se 
puede recuperar y que si es posible construir en este barrio. Este es el argumento para dicerle a la Administración que no estamos en ZAR.

\section{Mapa 7. Restricciones geológicas}
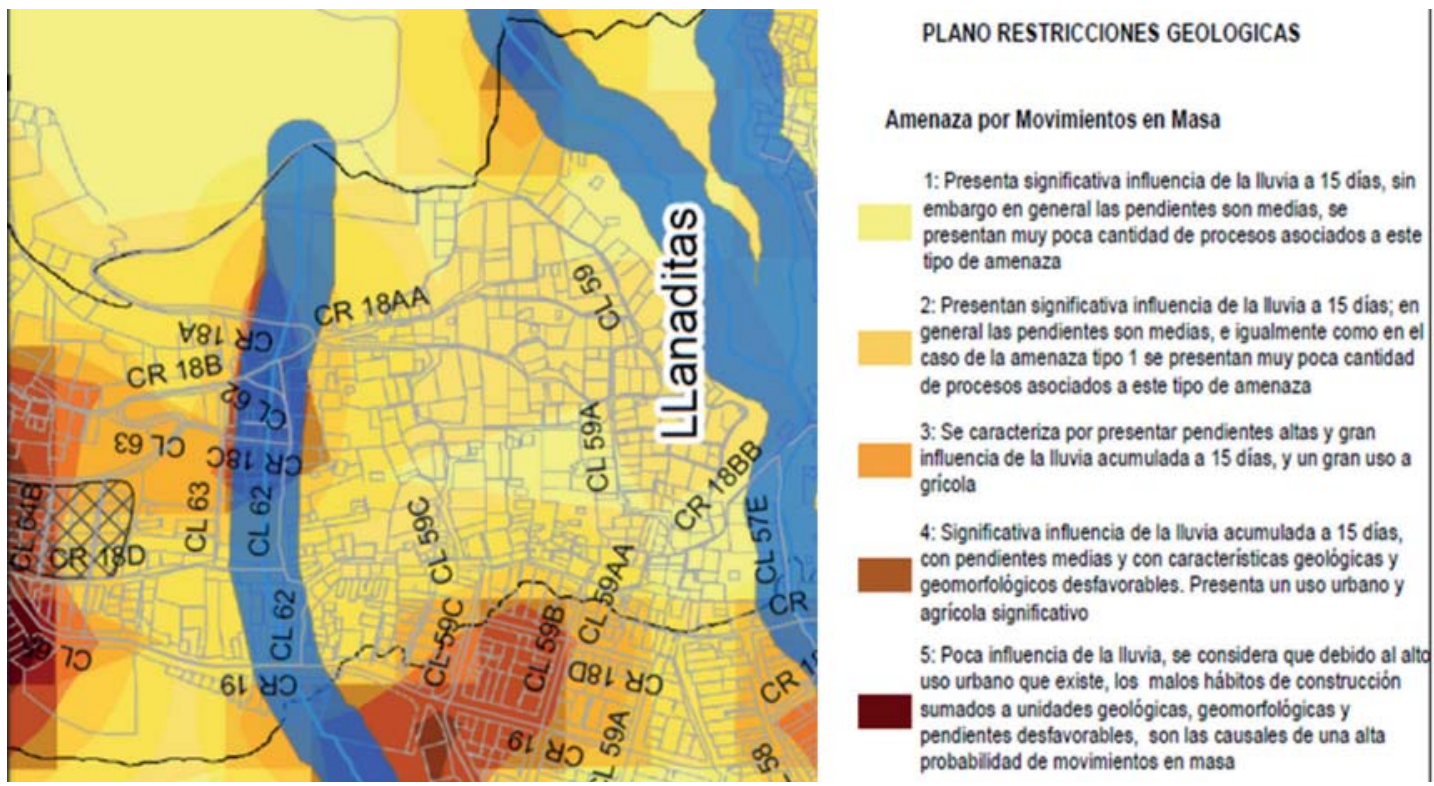

Fuente: Mapa de restricciones geológica Universidad Nacional de Colombia, sede Medellín.

El mapa entre más amarillo menos riesgo, más rojo mayor riesgo. Como se puede apreciar muchas de las zonas resultan desafectadas. Presentandose la mayor proporción de riesgo en cercanías a la quebrada Chorro Hondo y el caño que pasa por en medio del barrio por la calle 62 (quebrada La Aguadita). Frente a las cuencas de las quebradas si definitivamente hay que reubicar, lo unico que se podria pelear es la distancia del retiro para que no sea tan amplia, pero en base a unos estudios hidráulicos e hidrológicos con los cuales el barrio no cuenta y en prioritario realizarlos.

Como hemos venido insistiendo desde hace mucho rato, esto no es zona de riesgo, sino zona de alto costo. ¿Qué se necesita para evitar los deslizamientos? Por ejemplo muros de contención y rehabilitación, pero se necesita un proyecto específico para esto, no tanto a través de Presupuesto Participativo, que es como se ha venido gestionando hasta el momento, sino de presupuesto ordinario, ya que la inversión debe ser bien grande con el fin de buscar la protección de la comunidad.

Se le hace un llamado a la Administración para que se le quite el nombre al barrio de zona de alto riesgo por zona recuperable, ya que con ello se puede permitir un mejor desarrollo al barrio en todos sus aspectos, el hábitat, vías de acceso, caminos, viviendas con servicios, equipamientos y espacios públicos. La pregunta que surge es: ¿Si este sector es de alto riesgo, por qué cobran catastro y otros servicios?

El sector El Faro como tal no posee estudios de suelos por encontrarse en "suelo rural", por eso la importancia de generarlos de forma urgente, los que existen son del barrio Llanaditas. Sin embargo se ha solicitado por diferentes medios los 
resultados de estos estudios, como derechos de petición y a través de una comisión accidental, pero no los quieren entregar; se cree que es porque el resultado es positivo para la permanencia en el territorio de las comunidades, tal y como lo muestra el siguiente mapa que determina cómo quedaran afectada en términos de riesgo la comuna 8 en la próxima revisión del POT, que es una información recopilada por Planeación.

Mapa 8. Zonas Estables independientes y zonas inestables recuperadas.

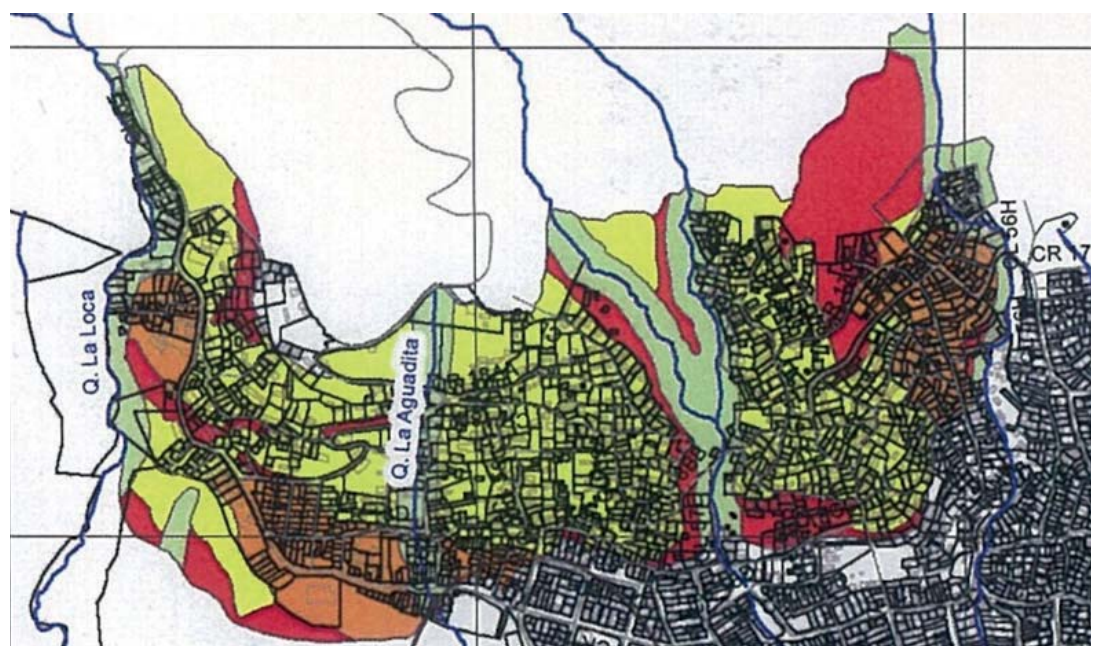

Fuente: Planeación Municipal. Medellín.

En color naranja se encuentran las zonas B (estables independientes) y en color amarillo las zonas C (inestables recuperables), es decir que estas dos zonas es susceptible de inversión estatal para mitigación del riesgo, sin embargo hace falta identificar por parte del DAP que zonas específicas del sector El Faro se encuentran en dicha clasificación. En cambio las zonas rojas son las zonas no recuperables y en verde las zonas de protección, en su mayoría retiros de quebradas disminuyen considerablemente si se le compara con lo propuesto por el POT.

Nótese la diferencia con el mapa anterior (el del POT de 2006) donde todo el barrio aparece como zona roja o no recuperable, en cambio este último muestra a partir de estos estudios micro zonificados como se han venido recuperando terrenos y hoy se encuentran aptos para la construcción y sobre todo para la puesta en marcha de proyectos de mejoramientos de vivienda, que es la principal necesidad de la comunidad.

Necesitamos que estos estudios planteen cuales son las obras de mitigación que se necesitarian y en qué lugares específicos, como la construcción de cunetas, lo mismo el alcantarillado, senderos, escalas, muros de contención, gaviones en llanta, en fin; por eso es importante que se realicen con la mayor prontitud posible y le sean socializados a la comunidad. Pero lo más importante es que se desafecten los suelos de zona de alto riesgo en la próxima revisión del POT, que es lo que más impide que lleguen los recursos a este territorio tan olvidado tanto por el Estado municipal como Nacional. 


\section{El Macroproyecto Cinturón Verde}

Dentro de los antecedentes de este macroproyecto de intervención urbanística se encuentra "El Plan Bordes" realizado por la EDU entre 2009 y 2010, que junto al proyecto "Más Bosques" de la Secretaria de Medio Ambiente implicaban generar una linea imaginaria que dividian el área urbana de la rural; a la final lo que se pretende es que de la "Cancha de Tavo" para arriba no hayan más casas, por eso se van a construir algunos parques y se pusieron una estatuas.

El EDU tenía en proyecto la construcción del "Ecoparque Llanaditas" hoy denominado "Parque Eco turístico y recreativo La Cancha" donde para su construcción se necesitarán retirar por lo menos 22 viviendas. La comunidad se pregunta ¿de qué nos sirve un parque, si a nosotros que hemos vivido tanto tiempo por aquí nos sacan, y por lo tanto no lo podemos gozar? Además que sacamos con un parque muy bonito y unas casas bien feas a su alrededor, esto resultaria en un sin sentido. Este es un proyecto muy bonito pero no es la necesidad más urgente de la comunidad, que es la vivienda. Necesitamos saber con imágenes y planos que es lo que se va a realizar, así mismo a qué nos atenemos y qué beneficios y perjuicios trae para nosotros. Posteriormente es necesario sentarnos en una Mesa de Concertación con la Administración donde definiremos cuáles serán los mejores proyectos para el desarrollo del territorio, teniendo en cuenta las ideas de la gente que lo habita.

Para nosotros lo más importante para cualquier tipo de intervención en Golondrinas y El Faro debe ser el desarrollo de obras de mitigación del riesgo, ya que con ello podemos garantizar una permanencia segura, además después podremos solicitar otro tipo de ayudas para el barrio, que gracias a la calificación como zona de riesgo, hoy día nos vemos excluidos de programas de acceso a servicios públicos, mejoramientos de vivienda y se nos impide la construcción de la carretera.

En proyecto Cinturón Verde piensa invertir un dinero, si le dijeran a la comunidad ¿en que invertiría ese dinero? Responderíamos que en Mejoramientos de vivienda y el tema de la carretera, un jardín infantil para ubicar a tanto niño pequeño, y una sede comunitaria con todos los equipos necesarios. Esas son cosas que realmente necesitamos como comunidad, y no un parque que es prácticamente para el turismo.

La propuesta de la Administración plantea una franja de transición entre lo urbano y lo rural, donde supuestamente se van a ver unos equipamientos "sellantes", que son una barrera, ahora ya no es el muro de Berlín sino estas obras como el sendero de la vida. La propuesta de la comunidad es que en esta franja se trabaje el proyecto de seguridad alimentaria con las huertas productivas. Ahí defenderiamos y garantizaríamos el derecho a la alimentación y la permanencia en el territorio. Así mismo la propuesta es conservar las viviendas existentes de la parte alta que pasarian a suelo suburbano, para que se les pueda garantizar también el Mejoramiento Integral.

En la zona de consolidación como la llama la Alcaldía, que sería en la parte urbana propiamente dicha, estaría el "eje de movilidad limpia", un supuesto monorriel que no se explica su construcción pues los principales problemas de movilidad de los habitantes tienen que ver con el acceso al centro de la ciudad, que es donde ocurren la mayoría de los viajes, y no hacia otros barrios periféricos de la zona 
nororiental. En esta franja estaría ubicados los proyectos de reasentamiento, que poco a nada han avanzado en los diseños y su conceptualización.

Todavía no está el proyecto como tal, solo unos bosquejos de planes maestros aún sin aprobar por Planeación Municipal, no se sabe aún por dónde va a pasar exactamente este cinturón verde o jardín circunvalar. Algunos concejales y la EDU dicen que el proyecto no afectará ninguna vivienda, y que la gente no debía de preocuparse, quieren que cuando llegue el proyecto nos coja como dice el dicho "con los calzones abajo", pero ahora que nos estamos poniendo los pantalones, ellos se están asustando porque estamos construyendo una propuesta alternativa desde las comunidades. A nosotros cuando nos dicen que estemos tranquilos, más preocupados debemos estar.

Mapa 9. Plan Maestro Cinturón Verde Llanaditas.

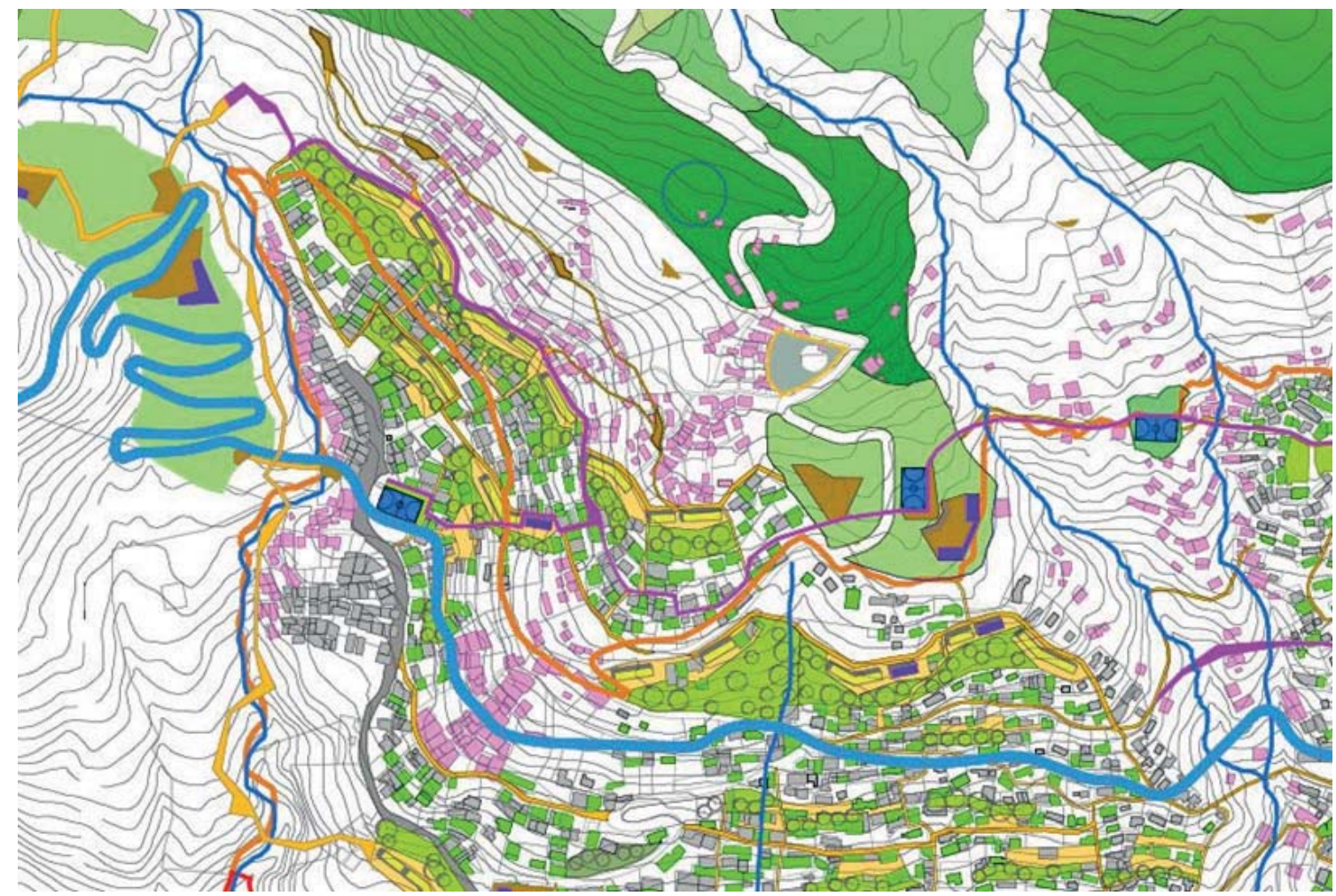

Captura parcial del Plan Maestro Cinturón Verde Llanaditas.

Fuente: EDU, 8 de septiembre 2013.

Lo que más preocupa a la comunidad es que va a pasar con las viviendas en color rosado que son las que requiere el proyecto para llevarse a cabo, que como se puede apreciarse en la imagen no son pocas. 


\section{Conclusiones.}

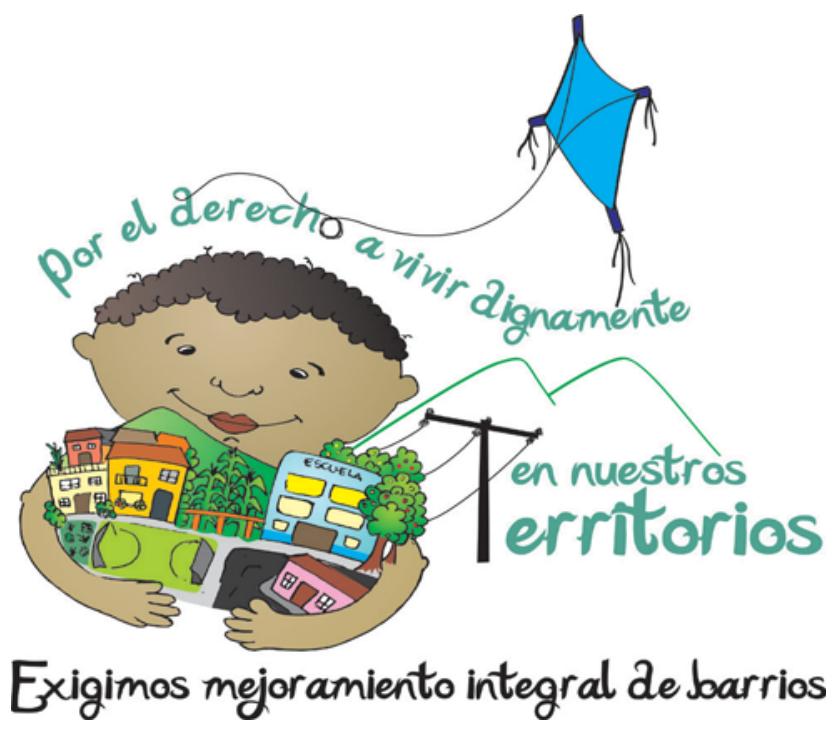

Mejoramiento integral de Barrios.

Estas propuestas se presentan al debate actual en la construcción del Plan Maestro del Cinturón Verde y la reformulación de POT que se hará el otro año en la ciudad de Medellín. Lo primero que proponemos es que frente a cualquier proyecto de intervención en nuestro territorio se haga bajo el enfoque de la Construcción Social del Hábitat (CSH) y no del Urbanismo Cívico Pedagógico que plantea la Administración, ya que nosotros debemos construir colectivamente unas propuestas como comunidad a través de talleres participativos con las organizaciones y el Plan de Desarrollo Local y bajo la asesoría de las universidad pública, para así poder concretar los diseños urbanísticos de los barrios y de las viviendas y los proyectos que se van a realizar.

Foto 6. Recorrido Territorial.

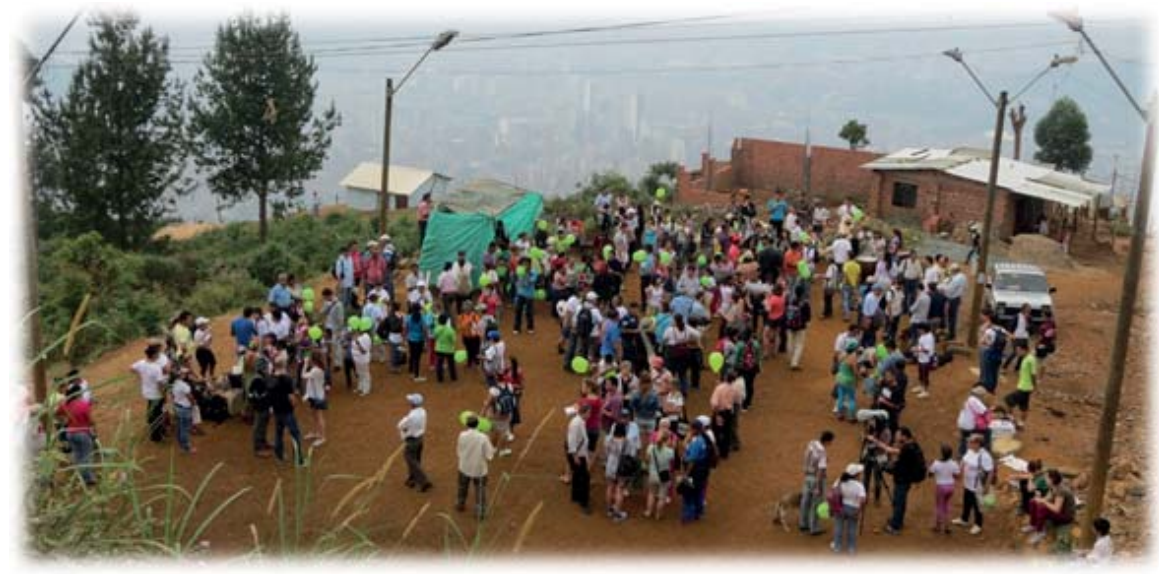

Corrido territorial "Por el Derecho a vivir Dignamente en Nuestros Territorios", Cancha de Tavo, 17 de marzo de 2013.

Fuente : Propia. 
Este debe ser un proceso, donde las discusiones deben bajarse de un lenguaje técnico a uno social que puedan comprender las comunidades, construyendo un proyecto de vida que incluya todas las particularidades de cómo nos soñamos el barrio, para posteriormente pasar a una etapa de diseño y de definición de prioridades en el presupuesto a invertir.

La propuesta contempla principalmente la ampliación de la cota del perímetro urbano de 2.000 hasta la altura de $2.060 \mathrm{msnm}$ (metros sobre el nivel del mar), mitigación del riesgo, acceso a servicios públicos domiciliarios (acueducto y alcantarillado, recolección de basuras y telefonía); el tema trascendental de la vivienda digna; dentro del espacio público la construcción de andenes; algunos equipamientos de carácter social como la sede comunal, un jardin infantil, un vivero, un parque infantil y un centro de salud que sirva a los cuatro sectores de la parte alta. Además de los cultivos colectivos como forma de evitar la expansión urbana y el fortalecimiento de los proyectos productivos. Así mismo es importante que Golondrinas y que El Faro sean reconocido como barrios por parte de Planeación Municipal.

Para nosotros lo más importante y prioritario para cualquier intervención es el desarrollo de obras de mitigación del riesgo, como la construcción de muros de rehabilitación, adecuación de senderos y escalas, y canalización de aguas lluvias y sucias; ya que con ello podemos garantizar una permanencia segura, además después podremos solicitar otro tipo de ayudas para el barrio, que gracias a la calificación como zona de riesgo hoy día nos vemos excluidos.

Es necesario un "Plan de Gestión del Riesgo" para que las familias puedan quedarse, con la consecución de recursos para la realización de los estudios de detalle pertinente, el diseño de las obras y la implementación de las obras civiles y actuaciones urbanísticas necesarias para la mitigación del riesgo y poder incorporar las áreas de riesgo a uso urbano permitiria que un número mayor de viviendas puedan quedarse en zonas calificadas como recuperables. Inicialmente la EDU avanzó en la definición de unos costos iniciales en el Plan Bordes, el cual argumentaba que para el barrio Llanaditas era necesario 11.500 millones de pesos para la mitigación del riesgo.

Se debe terminar de construir el acueducto, el alcantarillado y las obras complementarias; así mismo se debe evaluar el terreno donde van a ubicar el tanque de EPM, tanto técnicamente (si el terreno es propicio), como socialmente (que no afecte a muchas familias), esta obra deberá hacerse en la parte más alta del barrio para que no afecte a muchas familias y concertar con la comunidad los nuevos sitios propuestos.

Si como última opción tiene que haber algún afectado y es necesaria su reubicación, a la familia la deben reasentar en el mismo barrio o comuna. La exigencia es que se reciba casa por casa (puede ser usada) con escrituras y sin ningún tipo de recargo económico. La negociación deberá ser de manera colectiva, más no individual, logrando que las viviendas sean adecuadas para la cantidad de personas por familia, y que se garantice no subir el estrato mínimo en 10 años. Para superar el déficit habitacional proponemos reasentamientos en el lote del Batallón Girardot y el lote de la UdeA parte baja, pero que no las manden para Pajarito. 
Después de la mitigación, el mejoramiento integral de las viviendas es el segundo punto a concretarse en el proyecto, ya que es una necesidad inminente de la comunidad y uno de los objetivos fundamentales de la organización comunitaria, que es lograr una vivienda digna para todos los habitantes del barrio y de la comuna. Además de los subsidios ya existentes debe generarse otros mecanismos de gestión nacional e internacional para aumentar los rubros para dicho fin. Se necesitan en El Faro por lo menos 300 mejoramientos tanto estructurales como locativos de las viviendas, además de que les otorgue a las familias el título de propiedad y la legalización de su vivienda.

Planteamos la pavimentación de única vía de acceso al barrio desde La Virgen hasta la cancha de Tavo, con una ruta de transporte público que requiere un reversadero de colectivos (en dos plantas, debajo reversadero y encima la nueva cancha). Desde la cancha hasta "La Fonda" la construcción de unos rieles, para que pueda transitar un carro y las motos, ya que caminos prehispánicos no hay, estos ya desaparecieron, que es una de las excusas de la Administración para no intervenir en esta obra. Esto serviría para la seguridad y la salud de los habitantes, que tendrán por donde sacar un enfermo o un herido y/o que pueda entrar una ambulancia.

Foto 6. Estados de las vias de acceso.

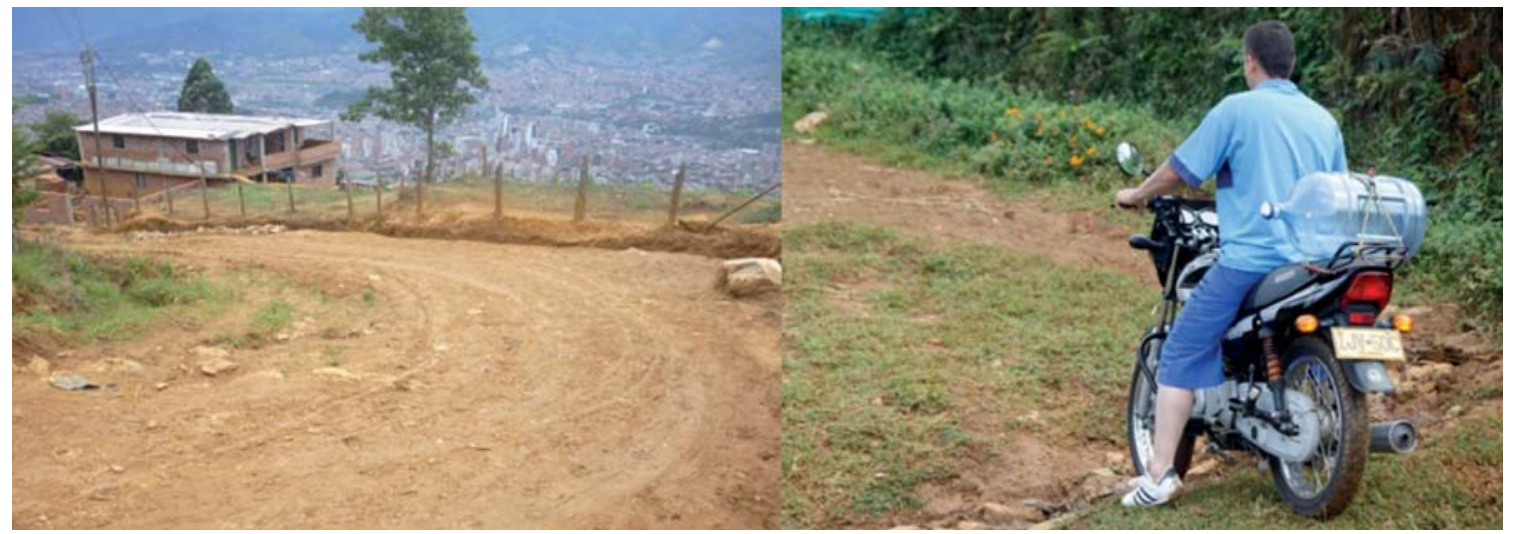

Fuente: propias.

En este territorio hay muchas parcelas, existen familias que tienen garantizada su seguridad alimentaria; se está sembrando café, maíz, papa, frutales y se tienen animales como marranos y gallinas. A su vez con las huertas se genera estabilidad en el terreno y se reduce el riesgo de ocupación con nuevas viviendas. Se deben fortalecer las huertas existentes y fomentar la creación de otras nuevas, pero que éstas tengan enmallado (para que cuando la gente pase no se roben los productos). La alcaldía deberá entregar unos lotes en comodato para sembrar cultivos y que sea administrado por la comunidad. Que sea con semillas naturales y no transgénicas y ayudas para los abonos. 
Foto 7. Proyectos seguridad alimentaria autónoma.

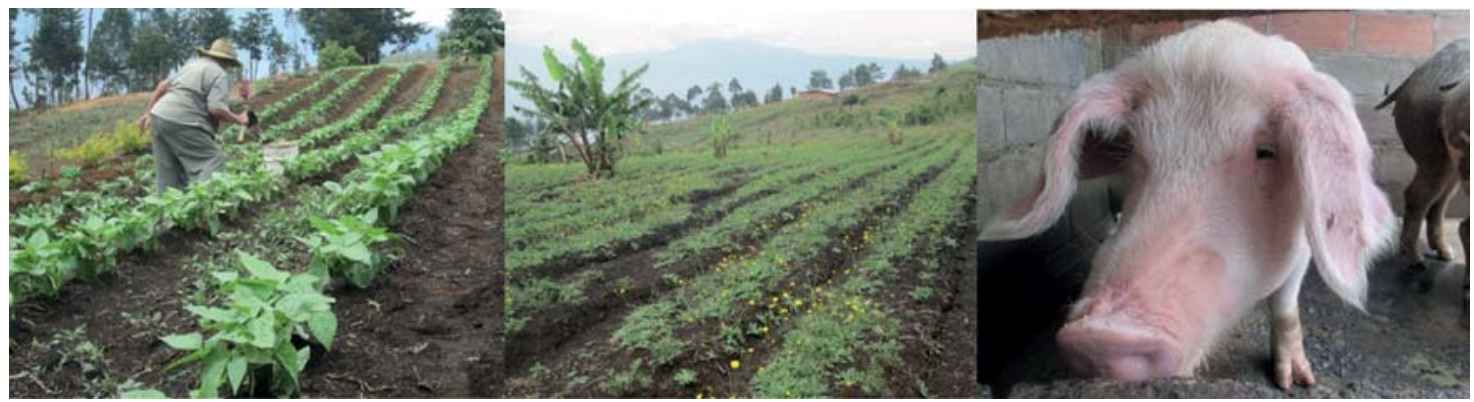

Fuente: propia.

Igualmente planteamos un "vivero mixto", que sea de árboles frutales y no maderables, para cuando el cinturón verde se implemente sean los árboles de la comunidad los que se siembren. Y contemplar plántulas para la seguridad alimentaria (paras las huertas) y plantas medicinales. Necesitamos subsistir por nuestros propios medios con las huertas, necesitamos que los productos de las huertas se puedan vender, fomentando la creación de una comercializadora y apoyando la transformación de las materias primas.

Proponemos que el área del Parque Central de Antioquia sea redefinida, y que sea de la Fonda del Tigre hacia arriba, que es donde está el camino prehispánico de piedra realmente ó el Camino de Cieza. A partir de alli debe generarse todo el tema de recuperación ambiental, teniendo prioridad las cuencas de las quebradas La Castro y La Loca.

El proyecto cinturón verde debe ser sostenible en el tiempo y garantizar la permanencia a los habitantes originarios, por tanto planteamos que el $20 \%$ de las familias del borde tengan proyectos productivos, y que del total del proyecto se destinen por lo menos el 10\% para este tema. El desarrollo no solamente son obras, también tiene que ser lo social, económico y cultural, apoyando a las organizaciones, las cuales estamos planeando el territorio y proponiendo ideas.

Para lograr poder concretar estas propuestas nosotros como habitantes del territorio y las organizaciones comunitarias que nos representan necesitamos avanzar en la definición de un modelo de ordenamiento propio, por eso la importancia de priorizar dinero en la "Jornada de Vida" para el tema de los estudios de diseño y formulación de proyectos de Mejoramiento Integral de Barrios en la comuna 8, donde El Faro es considerado como uno de los sectores prioritarios para la inversión, sin embargo la Administración nos niega el proyecto por temor a concertar con las comunidades una apuesta alternativa viable, construida con apoyo de la academia.

Finalmente se deben generar unos acuerdos con todo el barrio y la comuna 8 . Sentarnos con ISVIMED, EDU, Departamento Administrativo de Planeación (DAP) y el Área Metropolitana, y que se firmen unos acuerdos políticos en el Concejo de Medellín. En los debates debe estar presente la academia, especialmente la Universidad Nacional de Colombia sede Medellin, donde se puedan llegar a unos acuerdos mínimos entre la Comunidad y la Administración Municipal, dejándole claro a la Alcaldia que no se permitirá el desalojo de ningún hogar, ni ningún tipo 
de desplazamiento de la comunidad. Se respetará la permanencia de las familias en el territorio, ya que vale más cualquier comunidad que una obra de infraestructura.

\section{La Organización Comunitaria.}

Foto 8. Manifestaciones comunitarias en defensa del territorio.

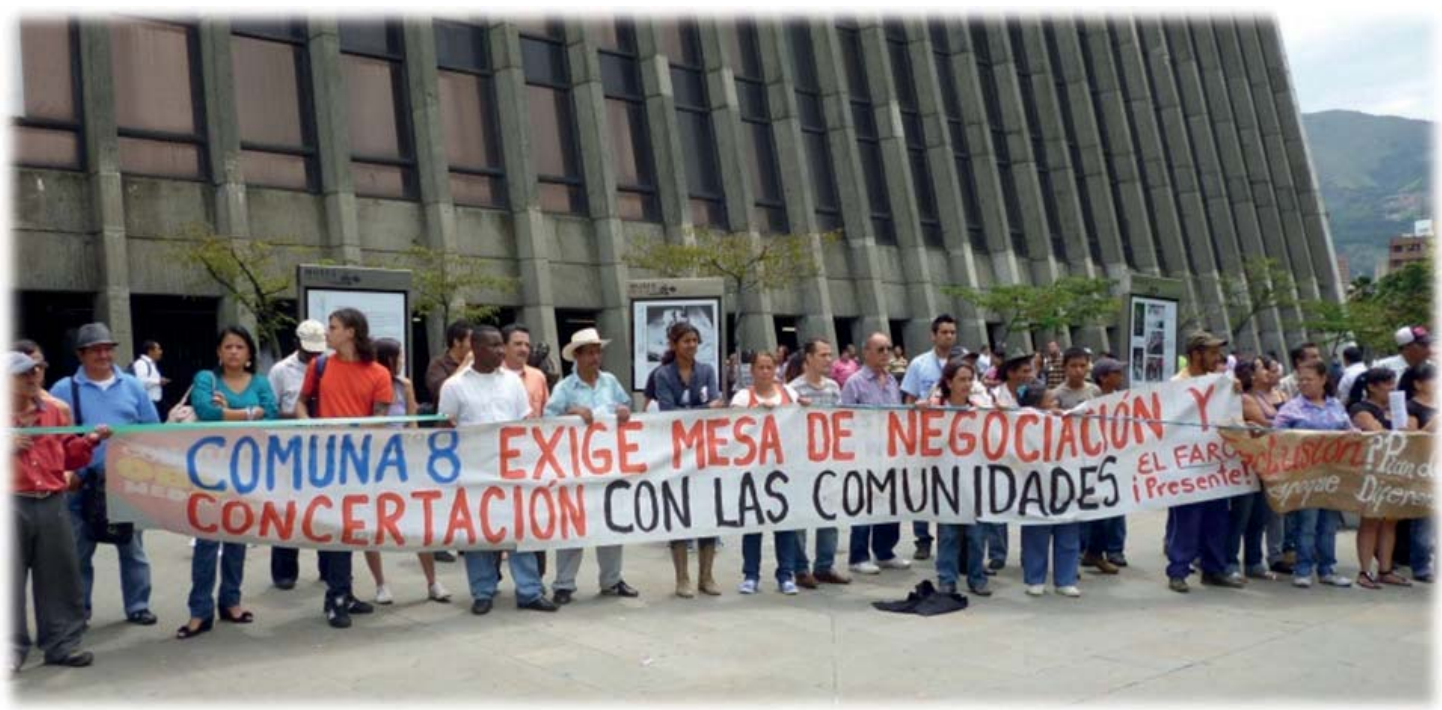

Fuente: Propia.

¿Nos vamos o nos quedamos, qué hacer?

En la encuesta comunitaria se preguntó a los habitantes si estaban de acuerdo con las intervenciones en el barrio. Un 60\% de los encuestados respondió que están de acuerdo pero bajo la premisa de que cuenten con la comunidad y que no la desplacen, ni desalojen, ni perjudique a ningún vecino, que respeten las viviendas y los terrenos, conservando los habitantes existentes y mejorando su calidad de vida. Tal y como lo decía una vecina "Siempre y cuando se piense en la vivienda y el hogar y no sólo en canchas y parques". Así mismo se plantean algunas condiciones como el respeto a la dignidad humana y los derechos fundamentales.

Un $40 \%$ dice no estar de acuerdo porque beneficia a algunas personas y perjudica a otras y porque nos salen afectando; uno de los encuestados manifiesta: "A los afectados nos mandan a otros barrios calientes y para una casa sin las condiciones necesarias, en unos apartamentos que nos sentimos como cigarrillos. No estamos de acuerdo que nos vuelvan a desplazar". Otros plantean que los proyectos no compensan lo que tienen en el barrio, como la casa y el lote.

Esto es muy importante tenerlo en cuenta porque es donde deben partir los principales acuerdos a los cuales debe responder la organización comunitaria que se genere en el barrio. Igualmente quisimos indagar qué haria la gente si las obras que van a construir lo afectaran, a lo cual un $18 \%$ dijo que se irian, según argumentan es mejor vivir en otra parte con todas las comodidades, ya que el barrio presenta dificultades de acceso por transporte, falta de colegios y puestos de salud, la carretera se encuentra sin pavimentar, y están sin acueducto 
y alcantarillado. Otros porque hay ancianos o discapacitados en sus casas y no se pueden movilizarse fácilmente.

Pero es bastante relevante que un $82 \%$ de las familias manifieste que se quedarian. Algunos de los argumentos son porque el barrio es tranquilo, es muy sano y no es tan violento ni hay pandillas, además de que la vista es muy bonita. Así lo dijo uno de los vecinos "Estoy muy amañado, somos el barrio más seguro de Medellín y no hay bandas".

También se plantea que se vive en armonía con la comunidad, existe trabajo en grupo, hay mucha integración y solidaridad, y es importante no romper el tejido social, ya que nuestro hábitat es construido entre todos. "Yo me quedaría más que todo por mis vecinos, acá tengo mis conocidos, y uno irse a otro lado donde uno no conoce a nadie. Además acá tenemos un buen ambiente familiar y características rurales". Finalmente una frase que puede resumir lo que piensan muchos vecinos "Este es el barrio que queremos, aquí vivimos muy bueno todos".

Es por ello que es necesario conformarnos y fortalecernos como organización para poder reclamar nuestros derechos de manera conjunta. De pronto cada uno ha tratado de solucionar su problema o dificultad de manera individual o cómo ha podido, necesitamos juntarnos como lo estamos haciendo, ya que este es un problema que necesita resolverse en comunidad. Es bueno seguir abriendo espacios de encuentro y darles continuidad. Igualmente es importante articular las luchas con otras organizaciones de la comuna 8 y de la ciudad, para lograr tener una mayor incidencia en el Cinturón Verde y el Plan de Ordenamiento Territorial.

\section{Lo que sigue... a gestionar el territorio.}

Es necesario fortalecer la organización comunitaria, ya que organizados logramos grandes cosas, porque dispersos no vamos para ninguna parte. Y hacerlo antes de que lleguen los proyectos, esto con el fin de tener una propuesta previa a cualquier intervención, donde nosotros como habitantes del territorio definamos finalmente lo que se va a realizar y bajo qué parámetros. Por eso la importancia de construir esta propuesta que vamos a defender en los diferentes escenarios donde se debata y se tomen decisiones.

Las negociaciones deben ser de carácter colectivo y bajo una organización que nos agrupe y defienda nuestros intereses, debemos dejar el individualismo y pensar en el otro como parte de una misma familia, la comunidad de El Faro. Colectivamente se pueden lograr cosas, necesitamos la unión y la movilización para hacerle presión a la administración, sino no tenemos incidencia. Necesitamos de la comunidad compromiso de seguir participando de todas las actividades programadas, y estar pendiente en que va cada uno de los proyectos y qué avances o retrocesos se van teniendo, y eso hace parte de la gestión de nuestra propuesta.

Un escenario que se puede potencializar para la discusión de la propuesta es reactivando la comisión accidental que se tiene con el Concejo de Medellín, pero eso sí con la participación abierta a la comunidad y no a beneficio de X o Y partido político; ampliando el tema de la carretera de acceso por el del mejoramiento integral del barrio, donde se traten las problemáticas de la vivienda, las obras de mitigación, el perimetro urbano y la restitución de derechos de la población desplazada y vulnerable. 
Finalmente, de todo esto ejercicio debe surgir la construcción de un Plan de Desarrollo Barrial o Plan de Vida de la Comunidad, que vaya en pro del mejoramiento integral del territorio, donde se identifiquen con mayor exactitud las problemáticas, reconociendo las particularidades de cada uno de los sectores y se avance en propuestas técnicas y socialmente viables, para poder pelear con argumentos claros, generando estrategias que nos conlleven a obtener una vida con dignidad. 


\section{Referencias Bibliográficas.}

Agudelo, L. (2000). Identificación, caracterización y valoración económica de los servicios ambientales prestados por ecosistemas localizados en el área de influencia del Valle de Aburrá. Medellín: Corantioquia. Universidad Nacional de Colombia Sede Medellin.

Aguilar, A. (2002). Las megaciudades y las periferias expandidas. Ampliando el concepto en ciudad de México. EURE, 28(85), 121-149.

Alcaldía De Medellín. (2006). "Proyecto de Regularización y Legalización urbanística. Diagnóstico Propositivo Multidimensional". Convenio Interadministrativo $\mathrm{N}^{\circ}$ 4800000855.

Alcaldía De Medellín. (2007). "Proyecto Urbano COR Alta". Documento técnico. Convenio Interadministrativo 4800001240.

Allen, A. (2003a). Environmental planning and management of the periurban interface: perspectives o an emerging field. Environment \& Urbanization, 15(1), 135- 147.

Allen, A. (2003b). Living between urban and rural areas. London: Development Planning Unit. University College of London.

Allen, A., Da Silva, N., \& Corubolo, E. (1999). Environmental problems and opportunities of the peri-urban interface and their impact upon the poor. London: Development Planning Unit. University College of London.

Bastidas, Wilder., Insuasty Rodrigrez, Alfonso. (2011). Caracterización de la oferta estatal, no gubernamental, privada y comunitaria en 8 barrios de Medellin, relacionados con oportunidades laborales y generación de ingresos. Univeridad de San Buenaventura. Obtenido de http:// web.usbmed.edu.co / librogrupodeinvestigacion.pdf

Cárdenas, A. (2006). Proyecto Urbano Integral Nororiental. Medellín: Alcaldía de Medellin.

Cotúa, Frederick y RÍOS, Diego. (2009). "Entre la quebrada Santa Elena y el cerro Pan de Azúcar". Memoria y territorio de la comuna 8. Documento compilatorio.

Departamento Administrativo de Planeación. (2010). Diagnóstico propositivo multidimensional del área de planeamiento Z3_MI_9 y parte de Z3_MI_8. Medellín: Subdirección Metroinformación.

Departamento Administrativo de Planeación. (2010). Encuesta de calidad de vida de 2009. Medellin: Alcaldía de Medellin.

Durán, F. (2005). Procesos de periurbanización y cambios en los modelos de ciudad. Revista de Sociología, 59-78. 
Fernandez, R. (2000a). Gestión ambiental de ciudades. Teoría crítica y aportes metodológicos. México D.F: Tipos Futura.

Fernández, R. (2000b). La ciudad verde. Teoría de la gestión ambiental urbana. Buenos Aires: Espacio Editorial.

Griffin, E., \& Ford, L. (1980). A model of latin american city structure. Geographical review, 70(4), 397-422.

López Pérez, J., Delgado Gómez, D., Posada Arrubla, A., Aguilar Maya, L., \& Vinasco Torres, L. (2006). Gestión ambiental territorial. Ideas básicas para su adopción en las interfases urbano rurales (IUR). En G. Morales (Ed.), Avances de investigación en ingeniería. Medellin: Sello Editorial Universidad de Medellín.

Madaleno, I., \& Gurovich, A. (2004). Urban versus rural no longer matches reality: an early public agro-residential development in periurban Santiago, Chile. Cities, 21(6), 513-526.

McElfish, J. (2007). Ten things wrong whit sprawl. Washington, D.C: Environmental Law Institute.

Mesa Interbarrial de Desconectados de Medellín. (2010). Proclama del III Encuentro de Desconectados. Medellin.

Naredo, J. (1997). Sobre el origen, el uso y el contenido del término sostenible. Obtenido de http://habitat.aq.upm.es/cs/p2/a004.html

RIOBACH. "Diagnóstico Comunitario Alternativo de las Comunidades de los barrios La Cruz y La Honda de la comuna 3 (Manrique)”. Octubre de 2010.

RIOBACH. (2010). Diagnostico Comunitario Alternativo de las comunidades de los barrios La Cruz y La Honda de la comuna 3 (Manrrique). Medellín.

Sisben. (2010). Encuesta SISBEN. Departamento Nacional de Planeación. 